Linköping Studies in Arts and Sciences No. 811

Social Robots as

Intentional

Agents

\title{
Sam Thellman
}





\title{
Social Robots as Intentional Agents
}

\author{
Sam Thellman
}


Linköping Studies in Arts and Sciences • No. 811

At the Faculty of Arts and Sciences at Linköping University, research and doctoral studies are carried out within broad problem areas. Research is organized in interdisciplinary research environments and doctoral studies mainly in graduate schools. Jointly, they publish the series Linköping Studies in Arts and Sciences. This thesis comes from the Division for Human-Centered Systems at the Department of Computer and Information Science.

(c) EY-NC This work is licensed under a Creative Commons AttributionNonCommercial 4.0 International License.

https://creativecommons.org/licenses/by-nc/4.0/

Edition 1:1

(C) Sam Thellman, 2021

ISBN 978-91-7929-008-5

ISSN 0282-9800

URL http://urn.kb.se/resolve?urn=urn:nbn: se:liu:diva-178806

Published articles have been reprinted with permission from the respective copyright holder.

Typeset using $\mathrm{X}_{\mathrm{H}} \mathrm{T}_{\mathrm{E}} \mathrm{X}$

Printed by LiU-Tryck, Linköping 2021 


\section{Populärvetenskaplig sammanfattning}

Robotar har länge varit begränsade till tillverkningsindustrin, men på senare tid har de blivit en del av många människors vardag, i form av exempelvis robotdammsugare, robotgräsklippare och självkörande bilar. Som en del av denna tendens utvecklas även så kallade sociala robotar, det vill säga robotar som är avsedda att fungera i sammanhang där sociala färdigheter är viktiga. Utvecklingen av sociala robotar skapar nya möjligheter, men också nya utmaningar. Förutom den tekniska utmaningen i att förse robotar med grundläggande sociala färdigheter, såsom att kommunicera väl, samarbeta och upprätthålla tillit, är den sociala robotens framgång även beroende av den tilltänkta användarens förmåga att interagera med teknologin.

Denna avhandling undersöker människors tendens att tolka robotar som föremål med vardagspsykologiska tillstånd, såsom vad robotar "vet", vad de "vill”, och vad de "tänker göra”. Avhandlingen presenterar empiriska resultat som tyder på att vi i vissa fall, på grund av avsaknad förståelse för hur teknologin verkligen fungerar, måste tillskriva sådana psykologiska tillstånd för att förutsäga robotars beteende. Vidare presenteras en metod för att undersöka sådana tillskrivningar experimentellt. I avhandlingen analyseras även problemet att tillskriva robotar "rätt sorts" psykologiska tillstånd, det vill säga de som gör det möjligt att förstå och förutsäga robotars beteende. Som en särskilt problematisk aspekt av detta bredare problem identifieras tillskrivning av den typ av trosföreställningar som är avhängiga människans förståelse för vad robotar kan och inte kan uppfatta i omgivningen. En viktig konsekvens av avhandlingens resultat är att de faktorer som ligger till grund för människors tolkningar av robotars beteende behöver tillägnas betydligt mer uppmärksamhet i framtiden. 


\begin{abstract}
Social robots are robots that are intended for social interaction with people. Because of the societal benefits that they are expected to bring, social robots are likely to become more common. Notably, social robots may be able to perform tasks that require social skills, such as communicating efficiently, coordinating actions, managing relationships, and building trust and rapport. However, robotic systems currently lack most of the technological preconditions for interacting socially. This means that until the necessary technology is developed, humans will have to do most of the work coordinating social interactions with robots. However, social robots are a phenomenon that might also challenge the human ability to interact socially. In particular, the actions of social robots may be less predictable to the ordinary people who will interact with them than the comparable actions of humans. In anticipating the actions of other people, we commonly employ folk-psychological assumptions about what others are likely to believe, want, and intend to do, given the situation that they are in. Folk psychology allows us to make instantaneous, unconscious judgments about the likely actions of others around us, and therefore, to interact socially. However, the application of folk psychology will be challenged in the context of social interaction with robots because of significant differences between humans and robots.

This thesis addresses the scope and limits of people's ability to interact socially with robots by treating them as intentional agents, i.e., agents whose behavior is most appropriately predicted by attributing it to underlying intentional states, such as beliefs and desires. The thesis provides an analysis of the problem(s) of attributing behaviorcongruent intentional states to robots, with a particular focus on the perceptual belief problem, i.e., the problem of understanding what robots know (and do not know) about objects and events in the environment based on their perception. The thesis presents evidence that people's understanding of robots as intentional agents is important to their ability to interact socially with them but that it may also be significantly limited by: (1) the extendability of the rich folk-psychological understanding that people have gained from sociocultural experiences with humans and other social animals to interactions with robots and (2) the integrability of new experiences with robots into a usable folk-psychological understanding of such technologies. Studying the formation and application of folk psychology in interactions with robots should therefore be a central undertaking in social robotics research.
\end{abstract}




\section{Acknowledgments}

In the acknowledgments section of my master's thesis I described myself as feeling like a "well-watered plant" under your supervision. Now, a number of years later, as I have finished my doctoral studies, I wonder: does that source of water never run out? Thanks to you, I look forward to continuing to spread my own academic seed and watch it take root in the fertile soil of future academia. Perhaps one day I will dabble in the pleasures of taking care of plants of my own. Should that day present itself, I shall think of you, Tom.

I am grateful for the support of my co-supervisors and colleagues. Thank you, Annika Silvervarg, Maartje de Graaf, and Jessica Lindblom for your excellent supervision. Thank you, Sofia Thunberg, Robert Johansson, Fredrik Stjernberg, and Nils Dahlbäck for friendship, encouragement, and advice. To past and present members of the Division for Human-Centered Systems at the Department of Computer and Information Science at Linköping University: thank you for making it one of my favorite places in the world!

Besides nourishment, plants need sunshine to flourish. Sofia, Stella, Magda - the moments I share with you are my time in the sun. I love you. Thank you, Sofia, for making this possible and for keeping me from losing sight of what is most important. I also want to thank my beloved parents Jonas and Maria for raising me with the confidence to take on big challenges and the courage to do things my own way. If it wasn't for all of you, I might not have ended up in the gardens of academia. 



\section{List of Publications}

\section{Paper I}

Thellman, S., Silvervarg, A., \& Ziemke, T. (2017). Folk-psychological interpretation of human vs. humanoid robot behavior: Exploring the intentional stance toward robots. Frontiers in Psychology, 8, 1962.

\section{Paper II}

Petrovych, V., Thellman, S., \& Ziemke, T. (2018). Human interpretation of goaldirected autonomous car behavior. In The 40th Annual Cognitive Science Society Meeting, July 25-28, Madison, Wisconsin, USA (pp. 2235-2240). Cognitive Science Society.

\section{Paper III}

Thellman, S., \& Ziemke, T. (2019). The intentional stance toward robots: conceptual and methodological considerations. In The 41st Annual Conference of the Cognitive Science Society, July 24-26, Montreal, Canada (pp. 1097-1103). Cognitive Science Society.

\section{Paper IV}

Thellman, S., \& Ziemke, T. (2021). The perceptual belief problem: Why explainability is a tough challenge in social robotics. ACM Transactions on Human-Robot Interaction, 10(3). doi:10.1145/3461781.

\section{Paper V}

Thellman, S., \& Ziemke, T. (2020). Do you see what I see? Tracking the perceptual beliefs of robots. iScience, 23(10), 101625.

\section{Paper VI}

Thellman, S., de Graaf, M., \& Ziemke, T. (in review). Mental state attribution to robots: A systematic review of conceptions, methods, and findings. Submitted to ACM Transactions on Human-Robot Interaction, June 2021. 



\section{Contents}

$\begin{array}{lll}\text { Abstract } & \text { iii }\end{array}$

Acknowledgments $\quad$ v

List of Publications vii

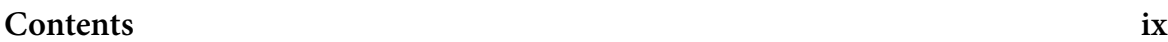

I Introduction 1

1 Overview 3

1.1 Motivation ..................... 3

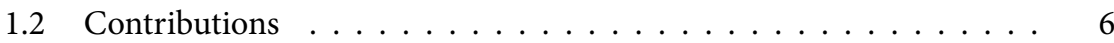

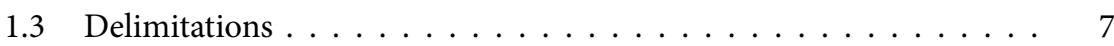

1.4 Outline ...................... 8

2 Social Robots 11

2.1 The Promise . . . . . . . . . . . . . . . . . . 11

2.2 Interacting Socially $\ldots \ldots \ldots \ldots \ldots$

2.3 What Robots Cannot Do (Yet) . . . . . . . . . . . . . . . 15

2.4 Technological Opacity . . . . . . . . . . . . . . . . 17

3 The Intentional Stance $\quad 21$

3.1 Intentional Systems Theory . . . . . . . . . . . . . . . 21

3.2 How It Works . . . . . . . . . . . . . . . . . . . . . . . . . . . . 23

3.3 Robots as Intentional Agents . . . . . . . . . . . . . . 25

4 The Intentionality Attribution Problem 29

4.1 Behavioral Congruency . . . . . . . . . . . . . . . . . . 29

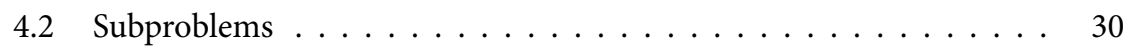

4.3 The Perceptual Belief Problem . . . . . . . . . . . . 33 
5 Methodology $\quad 37$

5.1 Observation of Behavioral Effects . . . . . . . . . . . . . 37

5.2 Inference of Attributed Intentional States . . . . . . . . . . . . . . . 39

5.3 Inference of Folk-Psychological Causes . . . . . . . . . . . . . . . . . . . . 40

5.4 Application . . . . . . . . . . . . . . . . . 41

6 Paper Summaries $\quad 45$

$6.1 \quad$ Paper I . . . . . . . . . . . . . . . . . . . . . 46

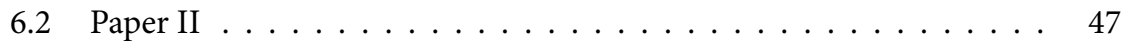

6.3 Paper III . . . . . . . . . . . . . . . . . . . . 47

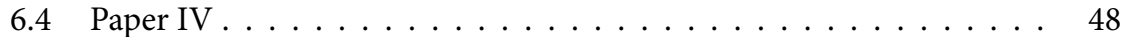

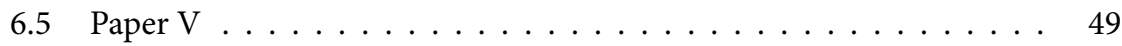

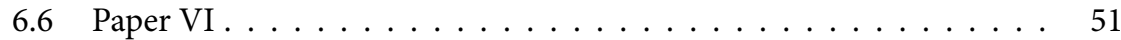

7 Discussion and Conclusions $\quad 53$

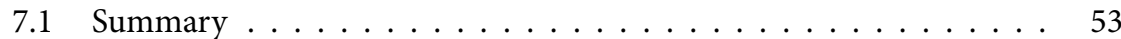

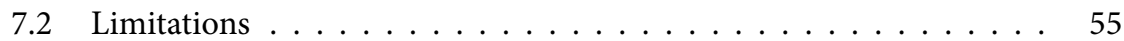

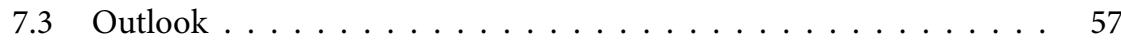

$\begin{array}{ll}\text { Bibliography } & 61\end{array}$

$\begin{array}{ll}\text { II Publications } & 71\end{array}$

$\begin{array}{ll}\text { Paper I } & 75\end{array}$

$\begin{array}{ll}\text { Paper II } & 91\end{array}$

$\begin{array}{lr}\text { Paper III } & 99\end{array}$

$\begin{array}{ll}\text { Paper IV } & 109\end{array}$

$\begin{array}{ll}\text { Paper V } & 127\end{array}$

$\begin{array}{ll}\text { Paper VI } & 153\end{array}$ 


\section{Part I}

\section{Introduction}





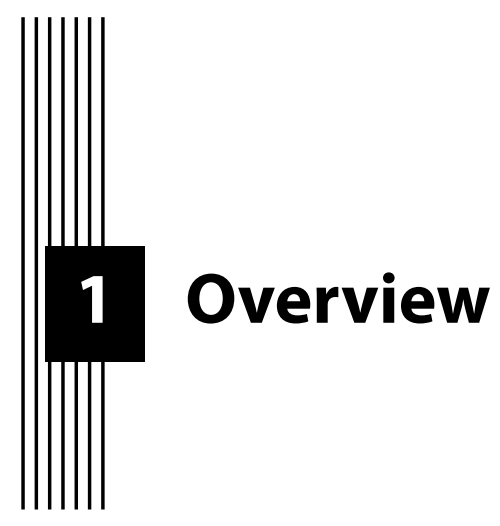

This chapter provides an overview of the purpose (Section 1.1), contributions (Section 1.2), and delimitations (Section 1.3) of the thesis, as well as an outline of the thesis structure (Section 1.4).

\subsection{Motivation}

The family had just returned from a midday trip to the beach when four-year-old Elsa came running to her father, yelling, "Dad, Rocky killed Bunny!" Bunny was Elsa's beloved furry rabbit toy that she played with in the garden before the beach. When the emotions surrounding Bunny's passing had settled a bit, she asked her father, "Why did Rocky kill Bunny?”. Elsa was visibly confused about the inner workings of Rocky her grandparents' lawn-mower robot. And so was her father. "Rocky probably didn't want to kill Bunny; maybe Rocky didn't see Bunny", he explained pedagogically, "or maybe it thought Bunny was a weed."

Thinking back over his explanation of Rocky's killing, Elsa's father realized that he in fact did not fully understand of how Rocky really worked. He had no idea how Rocky was programmed or what types of sensors and other hardware components hid under Rocky's green plastic exterior. Instead of referring to the physical mechanisms that govern Rocky's behavior, he was attributing intentional states to Rocky, that is, internal (mental) states that exhibit intentionality (the property of being directed toward some 
state of affairs in the world) ${ }^{1}$, such as beliefs (e.g., there is a tree ahead of me), desires (e.g., not to collide with things), and intentions (e.g., to turn away from the tree and keep moving). He then realized that he would likely not be able to provide a better or different explanation than the one he gave to his daughter; his understanding of the robot was only as good as his view of it as having particular beliefs and desires (such as to cut grass but not Bunnies, and to be able to spot the difference between the two).

"Is it safe to play with Pleo in the garden?", Elsa asked in the afternoon. "Sure", her father replied reassuringly, thinking that surely Rocky won't mistake that thing for grass. Then, two days later, to the great dismay of both of them, it happened again: Elsa found her toy dinosaur dismembered in the yard. Reflecting on his inability to either predict or explain Rocky's behavior (and the possible ramifications for his father-daughter relationship), Elsa's father kept thinking that it is a good thing that Rocky is not a social robot intended for human-robot interaction.

The folk-conceptual framework of beliefs, desires, intentions, and other intentional states, which Elsa's father relied on when explaining and predicting the behavior of Rocky, is ubiquitously expressed in everyday language interactions and structures how we as humans make sense of the behavior of others and how we decide to act in interactions with them (Dennett, 1989; Heider, 1958; Malle, 2006; Sellars, 1956; R. Gordon, 1986) ${ }^{2}$. For example, suppose Mary suddenly bumps into James while walking down a street. If James attributes Mary's behavior to an underlying intention to hurt him, he might perceive Mary's behavior as a hostile action and decide to respond with similar hostility. If, by contrast, Mary's behavior is attributed to a desire for intimacy, it might be perceived as friendly or flirtatious, and - if welcomed by James - might be reciprocated. James might also attribute Mary's behavior to unintentional causes, that is, causes beyond Mary's volitional control (e.g., maybe she stumbled), in which case it may be shrugged off as accidental. Importantly, folk psychology not only structures how we interpret the behavior of others but allows us to anticipate their actions, including how others will act in particular situations and how they will react to one's own actions. The ability to make instantaneous, unconscious judgments about the likely actions of others around us is a precondition for taking part in social interactions because our predictions affect our own decisions about how to act in the presence of others. For example, Mary's decision to bump into James in the street is

\footnotetext{
${ }^{1}$ The term intentional state is often contrasted with phenomenal state which is associated with phenomenal or conscious experience and refers to mental states that lack intentionality or "directedness" (Brentano, 2012), such as undirected feelings, emotions, and pain. Intentional states are those mental states that, in verbal descriptions, are usually followed by the determiner "that" and a proposition "..." as in she believed/wanted/hoped/feared/felt that ... Intentional idioms are also thought to exhibit referential opacity (e.g., Quine, 1961; Searle, 1983)

${ }^{2}$ It is worth noting that this is true regardless of whether folk-psychological constructs form a good basis for a scientific taxonomy of the mind, as doubted by some philosophers (e.g., Stich, 1983; Churchland, 1981). See also Section 1.3 on the delimitations of this thesis.
} 
likely based on expectations about how James will react (e.g., whether he will welcome or resent the gesture).

As humans, our understanding of others as intentional agents, i.e., agents with beliefs, desires, and other intentional states, is integral to how we interact socially. This includes our interactions with non-human animals. Animals such as household pets are widely assumed to possess the types of intentional states that are commonly ascribed to them. For example, most people likely believe that dogs really have the desire to eat, and might predict that a dog who is hungry and thinks there is food in the bowl will act on a real belief to satisfy its hunger. Such beliefs may be based on the underlying assumption that evolution has equipped some living organisms with the capacity to form intentional states. In contrast, most people likely believe that non-living things, including human-made artefacts, that are frequently talked about as if they had intentional states, do not necessarily really have the intentional states (or any other type of mental state) that are ascribed to them on an everyday basis. For example, people commonly describe the behavior of nation states and fictional characters in terms of beliefs and desires without necessarily believing that such ascriptions are veracious descriptions of these phenomena (Wendt, 1999; List \& Pettit, 2011) ${ }^{3}$. This naturally raises the question of why we ascribe intentional states to these entities, as opposed to attributing their behavior to whatever is assumed to be the real or true cause of the behavior.

In recent years, there has been increasing interest in the human tendency and ability to treat robots as intentional agents (Perez-Osorio \& Wykowska, 2020; Schellen \& Wykowska, 2019; Papagni \& Koeszegi, 2021, see also Paper VI of this thesis for a systematic review of the empirical literature). Researchers have investigated some of the determinants of the human tendency to attribute intentional (and other mental) states to robots, including factors such as a person's age (Manzi et al., 2020; Okanda, Taniguchi, Wang, \& Itakura, 2021), various motivational determinants (Waytz et al., 2010; Perez-Osorio, Marchesi, Ghiglino, Ince, \& Wykowska, 2019; Złotowski et al., 2018), robot appearance (Martini, Gonzalez, \& Wiese, 2016; Abubshait, Momen, \& Wiese, 2020), and robot behavior (Wallkötter, Stower, Kappas, \& Castellano, 2020; Abubshait \& Wiese, 2017; Terada \& Yamada, 2017). Other research focused on some of the effects of attributing intentional states, including trust in robots (Mou, Ruocco, Zanatto, \& Cangelosi, 2020), social attention (Wiese, Wykowska, Zwickel, \& Müller, 2012; Wykowska, Wiese, Prosser, \& Müller, 2014), cognitive performance (Wiese, Mandell, Shaw, \& Smith, 2019), and the abuse of robots (Keijsers \& Bartneck, 2018), and on what types of intentional states (and other mental states) people ascribe to robots as compared to other agents, such as humans or computers (Levin,

\footnotetext{
${ }^{3}$ For example, nations are commonly referred to as wanting to reach an agreement or as believing that a potential enemy is planning an attack, and some have even been described as "autistic" on account of their limited interaction with other states (Buzan, 1993).
} 
Killingsworth, Saylor, Gordon, \& Kawamura, 2013; Gray, Gray, \& Wegner, 2007; de Graaf, Malle, Dragan, \& Ziemke, 2018; Banks, 2020). However, despite the recent surge of interest in the role of mental state attribution in human-robot interactions, at the time of writing (summer 2021) relatively little research has been concerned with how attributions of specific intentional states affect how people actually interact with robots. In other words, previous research focused mainly on people's folkpsychological "theories" about robots without much attention to what people do with those theories - what Dennett (1991) referred to as the "craft" of folk psychology which, importantly, involves anticipating the social behavior of robots in interactions with them.

This doctoral thesis focuses on the human ability to interact socially with robots by treating them as intentional agents. Social robots, i.e., robots intended for social interaction with people, are a promising technology that may be instrumental in solving some of the anticipated societal challenges of the future - that is, if they are able to function in the social contexts for which they are intended. Attention is drawn to the fact that people commonly treat robots as intentional agents, independent of considerations about their physical constitution, functional design, or their status as potentially moral, cognitive, conscious or self-conscious entities. It is argued that people sometimes attribute the behavior of robots to underlying intentional states instead of, for example, computational or physical states, because it allows them to interact with these complex technologies without necessarily understanding how they "really" work, i.e., without any in-depth knowledge of the underlying physical and computational mechanisms. More specifically, when a robot's technical constitution or design (roughly, hardware or software specification) eludes people, they might still be able to interact with that robot based on the assumption that it will act in accordance with intentional states that are ascribed to it. The argument is made that, in a future where robotic technology is bound to become increasingly diverse and complex, the understanding - and prediction - of social robot behavior is likely to pose significant challenges for many people. For this reason, it will become increasingly important to investigate the socio-cognitive mechanisms that govern the attribution of behavior-congruent intentional states to robots, i.e., intentional states that are conducive to predicting the behavior of robots. To investigate this is the aim of the present thesis.

\subsection{Contributions}

The thesis contributes to the understanding of the scope and limits of people's ability to interact socially with robots by treating them as intentional agents. The contributed knowledge is important to the scientific understanding of human interaction with robots that are expected to interact socially with people (i.e., social robots), and has 
practical implications for human-robot interaction design (see Chapter 7). The main contributions are ${ }^{4}$ :

- An analysis of the intentionality attribution problem, i.e., the problem of attributing intentional states that are conducive to predicting the behavior of a robot (Papers III-IV).

- The development of a general research methodology for investigating the intentionality attribution problem empirically (Papers III-IV).

- Experimental findings regarding the folk-psychological assumptions that drive people's attributions of intentional states to robots, including that people apply their pre-existing folk-psychological understanding of others when judging the behavioral causes of a wide range of robotic systems (Papers I-II), and that the problem of attributing perceptual beliefs to robots is a particularly significant problem due to difficulties associated with inferring a robot's perceptual and cognitive capabilities (Paper V).

- Findings from analyzing existing literature on mental state attribution to robots (Paper VI), including that: the terminology used to describe mental state attribution to robots is diverse but largely homogenous in usage; the tendency to attribute mental states to robots is determined by factors such as the age and motivation of the human as well as the behavior, appearance, and identity of the robot; there is a computer < robot < human pattern in the tendency to attribute mental states that appears to be moderated by the presence of socially interactive behavior; there are apparent contradictions in the empirical literature that stem from different sources of evidence, including self-reported and nonverbal behavioral or neurological data; there are important gaps of research in the literature.

\subsection{Delimitations}

The scope of the thesis is delimited with respect to the following topics/issues:

Issue 1 The thesis does not adopt a position on the issue of what folk psychology actually is (or is not). For example, some scholars consider folk psychology to be a (tacit) theory (Sellars, 1956; Morton, 1980; Churchland, 1981; Stich, 1983; Fodor, 1987), while others consider it to be a type of internal simulation (R. Gordon, 1986; Goldman, 1989), or a combination of these two alternatives (Stich \& Nichols, 1992; Goldman, 2000).

\footnotetext{
${ }^{4} \mathrm{~A}$ more detailed description of the contributions of the individual papers of this compilation thesis is found in Chapter 6.
} 
Issue 2 The thesis does not adopt a position on the issue of what folk-psychological constructs (beliefs, desires, etc.) are (or are not). Some scholars advocate the view that they are internal representations (Dretske, 1991; Fodor, 1987; Pylyshyn, 1986). Dennett (1989) proposed that they are abstract patterns of behavior. Others have denied their existence altogether, considering them to be (moderately useful) fictions (Churchland, 1981; Stich, 1983).

Issue 3 The thesis does not adopt a position on the matter of what types of entities (e.g., robots) have or can have a mind, mental states (including intentional states), or mental capacities.

The thesis is neutral with respect to issues 1-3 for two reasons. The first reason is the absence of decisive empirical evidence, and the second reason is the lack of relevance to the thesis topic. The thesis assumes the widely held but also frequently disputed claim that, irrespective of issues 1-3, folk psychology, i.e., people's common-sense or intuitive understanding of the minds of themselves and others, is closely related to the following capacities ${ }^{5}$ :

A The capacity to attribute specific mental states to humans.

B The capacity to predict human behavior in a wide range of circumstances.

C The capacity to explain the behavior of humans in terms of mental states.

The main contributions of the thesis include arguments and empirical evidence that substantiate the claim that folk psychology is also important with regard to the ability to interact socially with robots, and, hence, that points A-C are to some extent also applicable to robots and robot behavior.

\subsection{Outline}

This thesis is written in the format of a Swedish compilation thesis. This means that the thesis consists of two parts: an introductory part, referred to in Swedish as the "kappa", and a part that contains the publications that form the basis of the thesis. The purpose of the kappa is to provide an overview of the thesis project and how each of the included publications contributes to the project.

\footnotetext{
${ }^{5}$ This claim is accepted by most philosophers of mind and cognitive scientists, including all (leading) scholars cited in this section (for an overview of the topic, see Nichols, 2006; Baker, 1999). For a recent review of deflationary accounts of the role of folk psychology in prediction and explanation on human behavior, see Borg (2018).
} 
The topic of the thesis is the scope and limits of the ability to interact socially with robots by treating them as intentional agents. Chapters 2-4 of the kappa are designed to explain why this is an important topic. Chapter 5 outlines a general methodology for studying the topic empirically. Chapter 6 summarizes the conceptual, methodological and empirical contributions of the included papers. Chapter 7 concludes the kappa with a summary and a discussion of the limitations as well as the broader implications of the thesis. 


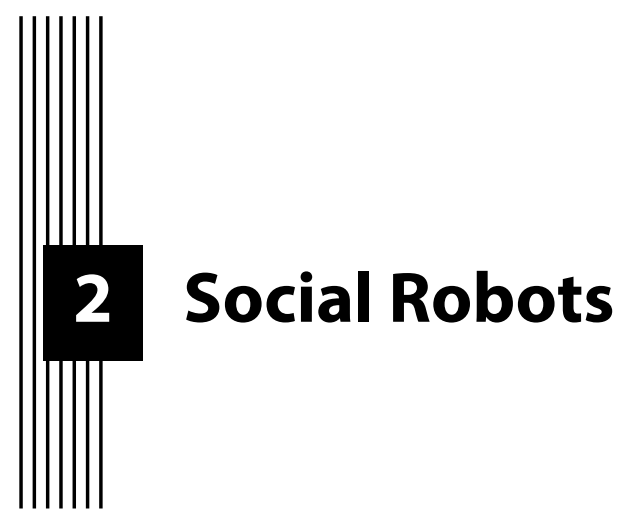

This chapter discusses the potential value and limitations of social robots. It is argued that social robots are a promising technology (Section 2.1), that interacting socially requires the command of folk psychology (Section 2.2), and that robots currently do not have a rich and usable folk-psychological understanding of the world to draw upon in interactions with humans (Section 2.3). Finally, the question is raised whether humans are able to understand robotic systems sufficiently well to interact socially with them (Section 2.4).

\subsection{The Promise}

Robotic systems, due to their potential as a technology that is capable of acting autonomously in the world, may provide solutions to some of the anticipated societal challenges of the future, such as the increasing pressure on the global health and social systems due to the aging world population ${ }^{1}$. For example, previous research has explored the potential of using robots in senior care (Broekens, Heerink, \& Rosendal, 2009; Čaić, Odekerken-Schröder, \& Mahr, 2018), education (Belpaeme, Kennedy, Ramachandran, Scassellati, \& Tanaka, 2018; Benitti, 2012), physical therapy (Eriksson, Mataric, \& Winstein, 2005), therapy for children with autism (Scassellati, Admoni, \& Matarić, 2012; Cabibihan, Javed, Ang, \& Aljunied, 2013), and in domestic

${ }^{1}$ The number of people over the age of 60 is expected to nearly double between the years 2015-2050 according to the World Health Organization (WHO, 2015). 
environments (de Graaf, Ben Allouch, \& van Dijk, 2019; Young, Hawkins, Sharlin, \& Igarashi, 2009).

The successful application of robotic technologies in these domains depends to some extent on the ability of robots to cope, not just with the physical world, but with the social one (Dautenhahn, 2007; Feil-Seifer \& Mataric, 2005; Brinck \& Balkenius, 2020) - and, more specifically, the human social world. That is, these areas require so-called socially interactive robots, or "social robots" for short, which rely on social skills and capabilities to interact with people (Fong, Nourbakhsh, \& Dautenhahn, 2003). This may include (but is not limited to) the ability to: communicate efficiently and in a manner that is appropriate to the situation at hand, coordinate actions and collaborate with others, maintain relationships (e.g., adapt to the emotions and attitudes of others), and to build trust and rapport. For example, according to Belpaeme et al. (2018), providing educational support may require a robot to "not only correctly interpret the user's responses to the educational content offered but also interpret the rapid and nuanced social cues that indicate task engagement, confusion, and attention."

Humans are experts in social interaction. Technology that adheres to human social expectations may therefore be experienced as generally more natural, effortless, enjoyable, and empowering (Fong et al., 2003; Reeves \& Nass, 1996). For example, such technology may reduce or eliminate the need to learn how to use an interface, such as a graphical user interface or a specific set of functional voice commands, as a precondition for interacting with it. This suggests that endowing robots with social capabilities may be useful beyond specific application areas such as the ones mentioned above, and that social robots - and other types of "socially intelligent" technology have the potential to become highly ubiquitous in society.

Some of the limitations of robotic systems that lack social awareness or intelligence are becoming increasingly clear as more robots come into contact with people. A good example of this can be found in some of the challenges associated with the development of automated vehicles (AVs). Whereas the automotive industry has made great strides during the past decade in the area of automated driving, it has become increasingly clear to industry experts that some of the crucial challenges involved in developing fully autonomous AVs may require endowing them with a form of social intelligence (Litman, 2021). Consider the following example from a recent report on the progress of implementing autonomous vehicles in the road transport system:

For safety sake motorists are advised to drive defensively, which means anticipating potential risks, such as wild animals and playful children. To do this, autonomous vehicles will need a database that categorizes, for example, fire hydrants as low-risk, pets on leashes as medium risk, 
and wild animals, such as kangaroos, as high risk. In addition, children sometimes dress in animal costumes, and adolescents in zombie variations. Most drivers can understand such risks. If I warn, "Watch out for teenagers dressed in zombie kangaroo costumes," you could probably understand the threat since you too were once a playful youth, but a computer would be flummoxed: such an unusual situation is unlikely to be in its database so the vehicle would either miss-categorize the risk, perhaps treating costumed fun-seekers as injured crash victims or a riotous mob, or stop and wait for human instructions. These systems can self-learn, and so could understand such behaviors and costumes if they become common, but cannot anticipate new conditions. (Litman, 2021, p. 24)

The type of social intelligence that is needed to handle the situation described in this scenario is the type of background of common-sense knowledge about other humans that adult human beings utilize intuitively in their daily interactions with others. In the following section, the possession of such knowledge will be discussed as a general precondition for being able to interact socially with others.

\subsection{Interacting Socially}

People's actions are typically assumed to be caused by intentional states, such as beliefs, desires, and intentions (Dennett, 1989; Heider, 1958; Malle, 2006; Sellars, 1956; R. Gordon, 1986). For example, the reader of this $\mathrm{PhD}$ thesis may assume the reason the thesis was written is that the author (a) wanted a $\mathrm{PhD}$ degree and believed the writing of a $\mathrm{PhD}$ was a necessary requirement for getting the degree, and/or (b) wanted to write it and believed that someone would read it. The fact that people commonly attribute both their own behavior and that of others to underlying intentional states is relatively independent of whether such attributions are veracious descriptions of the phenomena to which they refer (i.e., regardless of whether the attributed intentional states are in fact "real") or whether intentional constructs form a good basis for our scientific understanding of the human mind, as doubted by some philosophers of mind (e.g., Stich, 1983; Churchland, 1981) (cf. Section 1.3). In addition to whatever (else) intentional states may be (e.g., parts of inner theories, internal simulations, social experiences, cf. Section 1.3), they are (or are associated with) behavioral dispositions: things that make agents likely to take (or not take) specific actions in particular situations. For example, a person's belief that it is going to rain and their desire not to get wet may render it likely that the person will bring an umbrella when going to work in the morning. 
Intentional states are commonly assumed to be internal causes of behavior in the sense that they are not directly observable in an agent's external behavior but need to be inferred based on general knowledge about what others typically know, want, and intend to do in various situations and/or given certain behavior or characteristics. For example, one cannot directly observe that a person believes that it is going to rain but one may infer this based on knowing that people typically check the weather forecast in the morning. Knowing this, one can also predict that people will bring their umbrella to work on a rainy day. Such knowledge is commonly referred to as folk-psychological (R. Griffin \& Baron-Cohen, 2002).

As discussed in Paper III, the term folk psychology (also belief-desire psychology, naïve or intuitive psychology, or common-sense psychology) refers to all mindrelated knowledge that people have about themselves and others (R. Griffin \& BaronCohen, 2002). This includes empirical generalizations such as that people are more likely to want to carry their umbrella around on a rainy day and that people walking with a white cane might not know what is in front of them. People generally possess vast amounts of folk-psychological knowledge (Heider, 1958; Malle, 2006) that has accrued through years of social interaction and cultural exposure to folk-psychological narratives (Hutto, 2012), and they typically apply it tacitly and effortlessly (Nisbett \& Wilson, 1977; Clements \& Perner, 1994; Greenwald \& Banaji, 1995). Churchland (1981) stated, "each of us understands others, as well as we do, because we share a tacit command of an integrated body of lore concerning the law-like relations holding among external circumstances, internal states, and overt behavior. Given its nature and functions, this body of lore may quite aptly be called 'folk psychology."

Others can typically be assumed to act rationally in accordance with what they know and $w_{a n t^{2}}$. This includes humans as well as non-human animals, and to some extent interactive artifacts such as some computers and robots (this will be discussed in more detail in Chapter 3). Ascribing beliefs and desires that others do not have, or failing to recognize the ones that others do have, often results in misguided action prediction. For example, misunderstanding what a fellow road user knows or does not know about a traffic situation might lead to a mistaken prediction and a resulting traffic incident. In other words, the ability to reliably attribute beliefs and desires is central to the ability to interact socially with people.

Interacting socially involves predicting what others are going to do next in light of one's past social experience. The inability to predict action makes it difficult or impossible to interact, because deciding what to do in interactions depends on being able to reliably anticipate how others will react to events in the shared environment, in-

\footnotetext{
${ }^{2}$ This, of course, does not entail that people always act rationally and does not contradict the fact that human rationality is constrained by the nature of the human organism (Simon, 1955; Tversky \& Kahneman, 1974). However, it is worth noting that, in the context of social interactions, others' actions typically cannot be reliably predicted based on assumptions of irrationality.
} 
cluding how they will respond to one's own actions (FeldmanHall \& Shenhav, 2019). To predict specific others' (re)actions, one must have a reasonably accurate idea about what they know and want. However, without any empirical generalizations to rely on, any given situation affords an infinite amount of equally compatible belief and desire ascriptions (Csibra \& Gergely, 2007). Will John bring his umbrella to work? There is an endless list of possible reasons for why he might or might not, and without general knowledge of the likely intentional states of others there would be no means of weighing the plausibility of each reason. Hence, without folk psychology, the inferential problem space involved in attributing intentional states to others becomes intractable.

Without the capacity to form and sustain a rich folk-psychological understanding of others (sometimes also described as having a theory of mind; Baron-Cohen, Leslie, \& Frith, 1985, Premack \& Woodruff, 1978) it becomes difficult or impossible to reliably infer the intentional states (i.e., "reasons") behind others' actions. Folk knowledge about what others know and want in various situations constrains the problem space involved in action prediction by rendering some belief and desire ascriptions - and thereby some actions - as more plausible than others (cf. the "frame problem" in Fodor, 1983; Dennett, 2017). Folk psychology - in Churchland's above sense of a shared body of lore - is therefore by many considered a crucial prerequisite for the ability to interact socially with people.

\subsection{What Robots Cannot Do (Yet)}

Robots currently do not have a rich and usable folk-psychological understanding of the world to draw upon in interactions with humans, nor the capability to act competently based on such understanding (Yang et al., 2018). This means that the abilities of robots to interact socially are significantly limited ${ }^{3}$.

Endowing robots and other computer-based systems with folk psychology requires solving a more general problem that computer science has so far been unable to solve: the common-sense problem in artificial intelligence (AI) research (McCarthy, 1960; Davis \& Marcus, 2015; Lake, Ullman, Tenenbaum, \& Gershman, 2017; Shanahan, Crosby, Beyret, \& Cheke, 2020; Levesque, 2017). As argued by Dreyfus in his 1992 book What Computers Still Can't Do, "Intelligence requires understanding, and understanding requires giving a computer the background of common sense that adult human beings have by virtue of having bodies, interacting skillfully with the material world, and being trained into a culture." (Dreyfus, 1992, p. 3) According to Dreyfus, because of epistemological assumptions dictated by the information processing

\footnotetext{
${ }^{3}$ This may also constitute a significant problem for the recently conceived paradigm of Explainable Robotics (de Graaf \& Malle, 2017; Miller, 2019; de Graaf et al., 2018), which, to some extent, depends on robots to verbally explain their own behavior in appropriate and socially acceptable ways to improve human-robot interactions.
} 
model on which most AI research is based, this precondition of intelligent behavior necessarily appears to AI researchers as the need to find "a formal representation in which all the knowledge and beliefs of an average adult human being can be made explicit and organized for flexible use". While it suffices for our purposes to note that endowing computational technology with common sense remains one of the biggest challenges in the field of AI (Shanahan et al., 2020; Mitchell, 2021), the arguments presented by Dreyfus (1992) cast doubt on whether a satisfactory formalization of common-sense knowledge can ever be achieved.

It has been suggested that overly optimistic predictions about the development of artificial intelligence are often based on a "first step fallacy": the assumption that "narrow" intelligence is on a continuum with more "general" intelligence (such as intelligence based on common-sense understanding) and that advancement on a specific AI task is therefore a "first step" toward more general AI (Mitchell, 2021; Brooks, 2017; Dreyfus, 2012). Dreyfus quoted his brother, Stuart Dreyfus, stating that the fallacy is analogous to "claiming that the first monkey that climbed a tree was making progress toward landing on the moon" (Dreyfus, 2012, p. 92). In contrast, it has been suggested that the capabilities of computers and humans are not only profoundly different on the surface but categorically different. For example, Brooks (2017) made the distinction that computational systems exhibit performance but not competence (Brooks, 2017). Smith (2019) distinguished between reckoning as "the types of calculative prowess at which computer and AI systems already excel" and judgement as "dispassionate deliberative thought, grounded in ethical commitment and responsible action, appropriate to the situation in which it is deployed" and argued that "no historical or current approaches to AI, nor any I see on the horizon, have even begun to wrestle with the question of what constructing or developing judgment would involve." (Smith, 2019, p. XV-XVII)

Robots and other computer-based technologies currently lack the technological preconditions for interacting with people in ways that meet human expectations regarding social interaction. For example, robots are unable to communicate efficiently and coordinate actions with humans, except in highly specialized or task-specific domains. I have argued that interacting socially requires a background of commonsense knowledge about the minds and behavior of others, i.e., "folk psychology". No one knows if or when technological developments will allow robots to interact with humans based on a rich and usable folk psychology. However, the ideas and arguments presented in this section suggest that such technology is unlikely to develop any time soon - and until it does, humans will have to do most of the work coordinating social interactions with robots. 


\section{Dancing with robots}

To summarize the main points of the chapter made so far using the metaphor social interaction as dance (Shanker \& King, 2002), I have argued that: dancing robots are good (Section 2.1); to dance competently, dancers must be able to understand each other's behavioral dispositions as dancers (Section 2.2), and that; most current robots are incompetent dancers because they are unable to understand the dispositions of human dancers (Section 2.3; this section). This suggests that until the appropriate competencies have been developed, humans will have to be the "leaders" and robots will have to be the "followers" in the sense that humans will have to do most of the work coordinating social interactions with robots. The question we turn to in Section 2.4 , which is the main topic of the following two chapters, is whether humans are in fact competent to lead - i.e., are people able to understand robots sufficiently well to coordinate social interactions with them?

\subsection{Technological Opacity}

Robots are potentially technologically opaque (Surden \& Williams, 2016): it may be difficult to understand, in technical terms, why they take the actions that they do sometimes even for "experts". This makes them potentially unpredictable and, as a consequence, potentially difficult to interact with.

An illustrative example of technological opacity comes from aviation. The sophisticated autopilot systems available in commercial airplanes provide a significant amount of automated assistance to steering, navigation, landing, and other flying activities. However, they are also sometimes technologically opaque to the pilots who use them. For example, as captured in the industry catch-phrase "What's it doing now?” (cf. Sherry, Feary, Polson, \& Palmer, 2001), it is not uncommon for pilots to be surprised or confused by automated activities undertaken by an autopilot system (Surden \& Williams, 2016). Hence, an autopilot can undertake automated actions that may not be readily understandable or predictable to the pilots.

The phenomenon of technological opacity is generally related to the underlying complexity of technological systems (Surden \& Williams, 2016). Part of the reason that robots intended for social interaction may be technologically opaque is the complicated nature of social interactions. Interacting socially is a difficult task, so a system capable of engaging autonomously in social interaction with people is necessarily going to be complex. The hardware and software components of robotic systems are likely to interact in intricate ways to produce desired social behavior. In the case of such a complicated system, it may be particularly difficult to convey - in technical terms - what the system is doing and why, in a manner that is meaningful to people. 
Robots can be technologically opaque due to their hardware. For example, robots are typically equipped with sensors to collect information about the environment. Depending on the type of sensory equipment, the capacity to detect objects and events in the environment may vary. It is not always transparent to external observers what a robot has detected or is able to detect with its sensors. Moreover, even in cases where there is a relatively high degree of confidence that a robot has detected an object, it may not be obvious how the robot interprets or classifies that object. In cases of human-human interaction, it is generally safe to assume that a person who is looking at an object is also attending to it, and will draw similar conclusions about it (Clark \& Marshall, 1981). Part of the reason for this may be that, due to evolutionary constraints, there is a relatively small variation in perceptual and cognitive capability amongst members of the human species. Another reason may be that people have an intersubjective or cultural understanding of many things due to the fact that they are part of human society. In human-robot interactions, by contrast, such assumptions are precarious due to the considerable differences in the mechanisms by which people and robots, as well as different types of robots, perceive and understand the world. Furthermore, even if it is clear that a robot has registered the presence of a particular object or event, it is not necessarily obvious to an external observer if or how the robot will act based on that information.

Robots may also be technologically opaque due to their software. The software of computer systems may be so complex that the internal state transitions or behavior of the computer becomes difficult or impossible to predict even for the software engineer who programmed the system. For example, designers of chess-playing computer programs are consistently beaten in chess by their own programs (Dennett, 1971). Moreover, modern computer systems that are designed to take part in activities that involve some degree of unpredictability, such as the computers that govern the behavior of self-driving vehicles, often utilize a flexible programming technique called machine learning. Machine learning refers to computer algorithms that are able to automatically improve performance on some task over time through experience (Jordan \& Mitchell, 2015). In contrast to traditional programming techniques that rely on programmers to explicitly program computer systems with a set of rules that govern their behavior, machine learning algorithms operate by automatically encoding patterns detected in data into non-rule models - formulas or other complex data structures - that are difficult for people to follow (Surden \& Williams, 2016). The computer then uses these complex models to make automated decisions based on new data. As pointed out by Surden and Williams (2016), even though it is possible to "freeze" models after they have been generated or "trained" so that they remain constant when they come in contact with a person interacting with the computer system, machine learning algorithms are often designed to learn over time and change how they act as they encounter new data (e.g., based on the specific behavior exhibited by people or objects in the environment in which it operates). 
In sum, robots are unlikely to become less technologically opaque in the near future. In contrast to members of the human or animal species, who are bound to brains and bodies that develop at the speed of biological evolution, the internal constitution and capabilities of robots represents a "fast-moving target" - or better yet, multiple targets moving along different developmental trajectories. Robotic technology is likely to become more heterogenous as new uses are found and more complex as it is applied to solve increasingly difficult tasks, particularly those involved in social interaction. As a consequence, the underlying technology (i.e., hardware and software) of robotic systems - again, particularly those that are intended for social interaction - is unlikely to be well understood by the majority of people that are expected to interact with them. However, people might still be able to interact with robots (i.e., without understanding how they actually "work" in terms of technical constitution and design) based on the assumption that they will act in accordance with intentional states that are ascribed to them. In other words, when one can no longer hope to understand a robot by utilizing one's knowledge of physics or programming to anticipate its responses, one may still be able to interact with the robot by treating it like a (more or less) rational intentional agent. This is the topic of the following chapter. 
2. Social Robots 


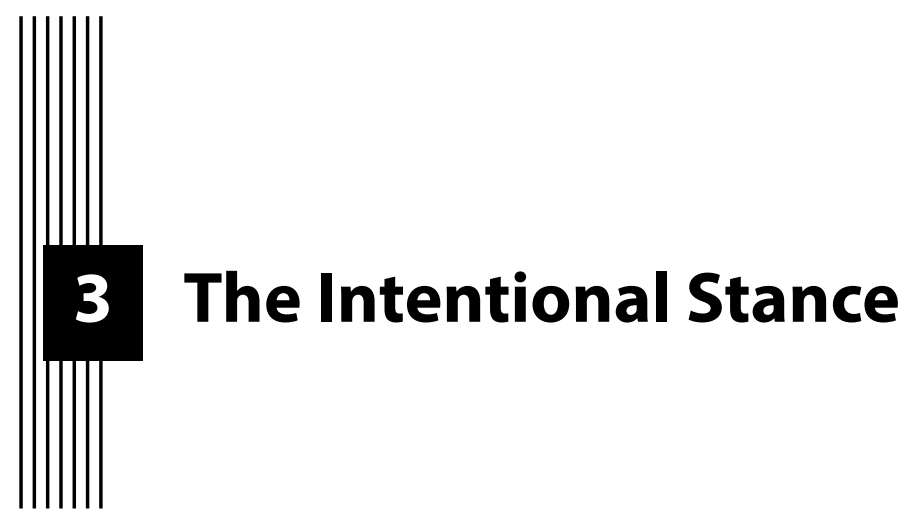

This chapter discusses people's understanding of social robots as intentional agents. It is argued that taking the intentional stance allows people to potentially interact with robots without necessarily understanding how robots "really" work (Section 3.1). Furthermore, it is pointed out that intentional prediction depends on underlying folkpsychological assumptions (Section 3.2). Finally, the applicability of folk psychology in interactions with robots is discussed (Section 3.3).

\subsection{Intentional Systems Theory ${ }^{1}$}

According to Dennett's intentional systems theory (Dennett, 1989), behavior can be understood, explained, and predicted from the point of view of three different levels of abstraction or "stances". At the lowest level of abstraction - the physical stance - behavior is viewed in terms of the physical properties of the system. One seldom adopts the physical stance to predict or explain the behavior of robotic systems because of the large number of critical variables in their physical constitution. Although possible in principle, tracing out the effects of the input energies all the way through the robot until some of its effectors are actuated is practically impossible (except in instances of breakdown where the condition preventing normal operation is easily locatable, such as when a robot runs out of power).

\footnotetext{
${ }^{1}$ Most of this section appeared in similar form in Paper IV.
} 
The medium level of abstraction is the design stance. When taking the design stance, one abstracts away from the physical details of the system and instead view behavior in terms of how the system is designed. Robotic systems are often too complex to understand from the design stance. People generally have little insight into the hardware and software design of robots, and, as discussed in Section 2.4, even those who do - e.g., programmers of robotic software - often cannot predict a robot's next move based on their knowledge as designers of the system. This means that robots are often, due to their technological opacity, practically inaccessible from the design stance or the physical stance.

The third and highest level of abstraction is the intentional stance. When taking the intentional stance toward a robot, one treats it as a rational agent whose behavior is governed by underlying intentional states, such as beliefs and desires, without considering its physical constitution and design in much detail.

In some cases, adopting the intentional stance toward an object is a useful strategy for predicting its behavior; in other cases, it is not. Dennett introduced the notion of an intentional system to denote objects or systems whose behavior can be (at least sometimes) explained and predicted only ${ }^{2}$ by being attributed to underlying intentional states, such as beliefs and desires (i.e., based on the intentional stance). Chessplaying computers, for instance, are intentional systems because not even the designers of chess-playing computer programs always manage to predict the program's next move in the game based on their knowledge of how the program is designed; the only reliable interpretative strategy available is the intentional one, which is to figure out what the program thinks that one is going to do next, and what the program wants to accomplish in the next couple of turns given its beliefs. The label "intentional system", however, does not extend to all objects. Although a person might predict that a thermostat will raise the room temperature in the morning because it wants to keep it at 73 degrees and knows that it has fallen during the night, the use of such intentional constructs in the interpretation of the thermostat's behavior does not add predictive value above and beyond the corresponding non-psychological interpretation. A simple thermostat, therefore, is not an intentional system.

It is crucial to understand that what is and what is not an intentional system is not subjectively "in the eye of the observer". The point is that a person playing against a chess-playing computer does not choose whether to adopt the intentional stance; there is simply no other feasible way (for any person playing against a modern chessplaying computer, as far as is known) to predict the computer's moves. Furthermore, it is important to note that the fact that an object or system is an intentional system

\footnotetext{
${ }^{2}$ The word "only" was not part of Dennett's original description of intentional systems (Dennett, 1971). However, in later work Dennett clarified his account of intentional systems, excluding systems (e.g., thermostats) whose behavior can be sufficiently explained using non-psychological interpretation (Dennett, 1989).
} 
does not necessarily mean that it really has beliefs and desires; it only means that one can explain and predict its behavior by ascribing beliefs and desires to it (Dennett, $1971)^{3}$. A third important point is that what kinds of robots (and other systems) are intentional systems is ultimately an empirical question - in the same sense that it turned out as a matter of fact that the moves of a chess-playing computer can only be predicted reliably based on the intentional stance.

In human-robot interactions, intentional prediction and explanation is not only common (see Paper VI for a review of the empirical literature) but also works when no other sort of prediction is feasible. That is, in some cases people treat robots as intentional agents with beliefs, desires, intentions, and so on, independent of considerations about their physical constitution, functional design, or their status as potentially moral, cognitive, conscious or self-conscious entities. Hence, taking the intentional stance allows them to potentially interact with robots without necessarily understanding how robots "really" work, i.e., without any in-depth knowledge of the underlying physical and computational mechanisms.

\subsection{How It Works}

How do you predict a robot's next move based on ascribing intentional states to it? Here is Dennett's explanation:

first you decide to treat the object whose behavior is to be predicted as a rational agent; then you figure out what beliefs that agent ought to have, given its place in the world and its purpose. Then you figure out what desires it ought to have, on the same considerations, and finally you predict that this rational agent will act to further its goals in the light of its beliefs. A little practical reasoning from the chosen set of beliefs and desires will in most instances yield a decision about what the agent ought to do; that is what you predict the agent will do. (Dennett, 1989, p. 17)

In every imaginable situation, there is an infinitely large space of beliefs and desires (and other intentional states) that an agent possibly could have. The problem of attributing the intentional states that an agent "ought to have" (cf. the above quote) is therefore underdetermined by the data available to the observer (Csibra \& Gergely, 2007). This means, the observer must rely on assumptions about the agent that render

\footnotetext{
${ }^{3}$ It might be worth noting, however, that Dennett's own position - to which there are several alternatives (e.g., Churchland, 1981; Fodor, 1975) - is that "what it is to be a true believer is to be an intentional system" (Dennett, 1989, p. 15). This means, according to Dennett, that the intentional states of chessplaying computers, robots, and other artefacts that potentially qualify as intentional systems may be just as real as those of humans.
} 
some candidates for ascription as more plausible than others (see Figure 3.1). Folk psychology - i.e., knowledge about the minds and behavior of others gained from social experiences (cf. Section 2.2) - includes general knowledge about what others typically want, believe, and intend in various circumstances. For example, folk psychology includes generalizations such as that people who agree to a meeting generally turn up at the specified time and location, that a person who is thirsty might want a drink, and that people who believe in the existence of unicorns may also believe in the existence of dragons. In interpretations of human behavior, people are usually able to exclude unlikely ascriptions effortlessly based on the tacit assumption that folk-psychological generalizations apply to the situation at hand (Fodor, 1983; Dennett, 2017). Folk psychology thus provide "satisficing" solutions (Simon, 1956) to the computationally intractable problem of attributing intentional states, and thereby allows people to make instantaneous, unconscious judgments about the likely actions of others, and therefore, to interact socially with them.

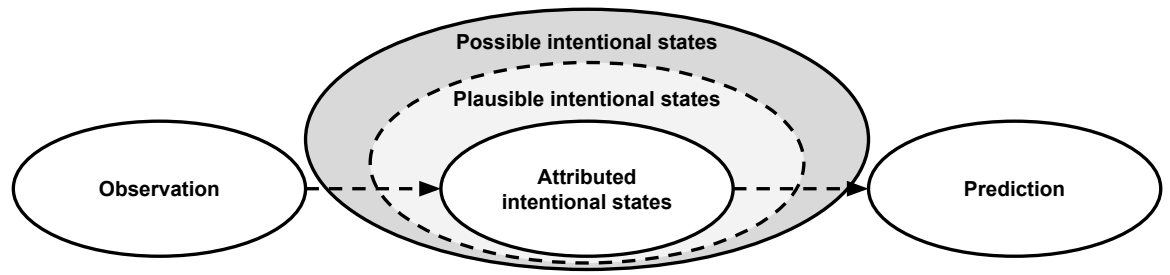

Figure 3.1: Folk psychology constrains the problem space of attributing intentional states by rendering some candidate ascriptions as more plausible than others.

People possess vast amounts of folk-psychological knowledge that has accrued through years of social interaction and cultural exposure to folk-psychological narratives (Hutto, 2012; Heider, 1958; Malle, 2006). Several scholars of philosophy of mind and cognitive science, who are in substantial disagreement over what folkpsychological constructs, such as intentional states, really are and how they can be scientifically explained (e.g., Churchland, 1981; Fodor, 1975; Dennett, 1989; Stich, 1983; Searle, 2008), have drawn attention to the remarkable precision with which people are able predict and explain behavior based on folk psychology (Daly, 2013). For example, Pylyshyn, who called folk psychology "undoubtedly the most successful predictive scheme available for human behavior"4 (Pylyshyn, 1980), illustrated this point using the following example:

\footnotetext{
${ }^{4}$ Similar remarks have been made by other philosophers of mind. Dennett (1989), for example, described the use of folk psychology in interpersonal interaction as "practically indispensable." Fodor (1987) stated its predictive power is "beyond rational dispute." Stich and Nichols (1992) stated that "by exploiting these intentional descriptions, people are able to ... predict each other's behavior, often with impressive accuracy." Morton (1980) stated, "When we try to describe our involvement in social life we have no real choice but to use the folk-psychological vocabulary."
} 
Suppose you are standing on a street corner and observe a sequence of events that might be described as follows. A pedestrian is walking along a sidewalk. Suddenly the pedestrian turns and starts to cross the street. At the same time, a car is traveling rapidly down the street toward the pedestrian. The driver of the car applies the brakes. The car skids and swerves over to the side of the road, hitting a pole. The pedestrian hesitates, then goes over and looks inside the car on the driver's side. $\mathrm{He}$ turns to a telephone booth at the corner and dials the numbers 9 and 1 .

What has happened? Why did the pedestrian run to the phone booth? What will he do next, and why? (Pylyshyn, 1986, p. 3)

Pylyshyn (1986) points out that it is in virtue of folk psychology that human adults are able to answer these and similar questions. He also points out that neither an answer in physical terms or biological terms (e.g., "by innervating a cycle of opposing tenser muscles, which causes the position of one foot to be placed ahead of the other") would be an adequate answer to any of these why, what, or how questions. Instead, explaining human behavior generally requires a psychological account, i.e., an explanation couched in intentional terms. Again, such explanations depend on folkpsychological assumptions about the explanandum. For example, certain assumptions must be made about the pedestrian in the above vignette, such as that he or she perceived of the event as an emergency, knows what to do, remembers the emergency services number, and so on (Pylyshyn, 1986). Hence, the reason that people are able to predict the actions of specific others in specific situations, based on the intentional stance, is that they are able to form and sustain general folk-psychological knowledge that is applicable in a wide range of circumstances.

\subsection{Robots as Intentional Agents}

In contrast to the case of human-human interaction, people typically have very little experience interacting with robots. To what extent is folk-psychological knowledge gained from social experiences with humans and animals applicable in interactions with robots? This depends on the extent to which it is possible and feasible to design robots with (what appears to the external observer as) a human- or animal-like mind.

There is ample evidence that people draw on folk psychology in their interpretations of robots (and other computer-based artefacts, cf. Reeves \& Nass, 1996). For example, Lee, Lau, Kiesler, and Chiu (2005) demonstrated that participants in their study made different estimations of a robot's knowledge about national landmarks when the robot spoke English versus Chinese and they were told that the robot was made in the US versus China. Similarly, participants in an experiment by Powers et al. (2005) made different estimations of a robot's knowledge of dating norms depending on whether 
the robot was endowed with a female or male voice and appearance. People's reliance on pre-existing folk-psychological knowledge about humans and animals can thus be exploited by designers of robotic systems to evoke specific attributions of intentional states (e.g., specific knowledge) to specific robots. This means that there is an incentive to design robots that appear to have a human- or animal-like mind (for a discussion of additional ways that evoking perceptions of mind in robots can positively affect human-robot interaction, see Wiese, Metta, \& Wykowska, 2017).

There are, however, also cases where human or animal folk psychology appears inapplicable to robots. For instance, many of the goals or desires that are intrinsic to living organisms are not necessarily held by robots (e.g., related to survival and reproduction). Moreover, the mechanisms that govern belief formation and action in robots and humans (e.g., sensory perception and decision making) differ considerably, and, as argued in Section 2.3, are likely to differ in the foreseeable future. This means that assumptions about what humans typically want and believe in various circumstances do not necessarily apply to robots. Hence, there are both cases where people's folkpsychological assumptions about humans seem applicable and cases where they do not seem applicable, and it is generally not yet clear how far human or animal folk psychology can take people in interactions with robots.

Given the potential limitations in the extendability of human or animal folk psychology to interactions with robots, it might be necessary for people to form a folkpsychological understanding of robots based on experiences with them. The fact that people are able to sustain different mental models of the minds of many different kinds of living organisms, including, for example, pet animals such as cats and dogs, suggests that this may be possible. However, as discussed in Section 2.4, the capabilities and limitations of robots represent - due to the lack of biological and evolutionary constraints - multiple targets moving in different developmental trajectories. This might significantly challenge the human ability to make useful folk-psychological generalization about robots. For example, consider the human reliance on being able to infer what others know (and do not know) based on their gaze behavior. Whereas the human eye has the largest ratio of exposed sclera in the eye outline and a considerably paler sclera compared to other primates, the sclera of primates such as the gorilla have similar coloration to that of the skin around the eyes to remain "gaze camouflaged" (Kobayashi \& Kohshima, 1997). This makes the perceptual beliefs of a gorilla difficult to infer (for humans and gorillas alike). Now, consider the challenge of ascribing the appropriate perceptual beliefs to various types of robots encountered in different contexts, such as in traffic, in a nursing home, or in a café. These robots may be equipped with virtually any kind of sensory technology, and their external appearance or behavior (e.g., the presence or absence of eyes, body orientation) might, in contrast to most humans or animals, not necessarily be a good reflection of what they actually see and know. Therefore, experiences interacting with these different 
types of robots might not be a sufficient basis for forming folk-psychological generalizations that are applicable in interactions with other types of robots. In other words, the integrability of people's experiences with robots into a rich and usable general folk-psychological understanding of robots is largely an open question.

To summarize, the scope and limits of people's ability to interact socially with robots by treating them as intentional systems or agents, i.e., agents whose behavior is most appropriately predicted by being attributed to underlying intentional states, depends on the following two open questions, which are henceforth referred to as the extendability question and the integrability question:

The extendability question: To what extent is folk-psychological knowledge gained from sociocultural experiences with humans and non-human animals applicable in interactions with robots?

The integrability question: To what extent can experiences from interactions with robots be integrated into folk psychology and be flexibly applied in interactions with (other/different types of) robots?

The extendability question and integrability question can be represented visually in the form of a two-dimensional graph with low and high endpoints. A hypothetical robot that is positioned in the higher spectrum of the extendability dimension (Figure 3.2 , left) is easy to interact with because the folk-psychological knowledge that people have gained from social interactions with humans and exposure to folk-psychological narratives are applicable and form a reliable basis for predicting the robot's behavior. Such a robot is, of course, unlikely to exist in the near future (partly for the reasons detailed in Section 2.3 on the current technological limitations of robots). A robot positioned in the higher spectrum of the integrability dimension (Figure 3.2, middle) is easy to interact with because people are able to reliably predict its behavior based on folk-psychological knowledge gained from interacting with other types of robots. This type of robot may be relatively uncommon in a future where the technological landscape is highly diverse in terms of the capabilities and limitations of different types of robotic systems. Finally, a robot positioned in the lower spectrum of both the extendability and integrability dimensions (Figure 3.2, right) may be difficult to interact with due to the fact that its behavior is not necessarily reliably predictable based on folk-psychological knowledge gained from either experiences with humans or (other) robots.

Clearly, no single study or series of studies can provide conclusive answers to the extendability and integrability questions. However, this thesis contributes toward a deeper understanding of these questions by developing and applying research methods to investigate some of the folk-psychological assumptions that guide people's in- 
teractions with robots, including the conditions under which such assumptions give rise to attributions of intentional states that are (in)conducive to predicting behavior. In the following chapter, I analyze the problem of attributing behavior-congruent intentional states to robots by breaking it down into distinct subproblems that are better suited for empirical investigation.
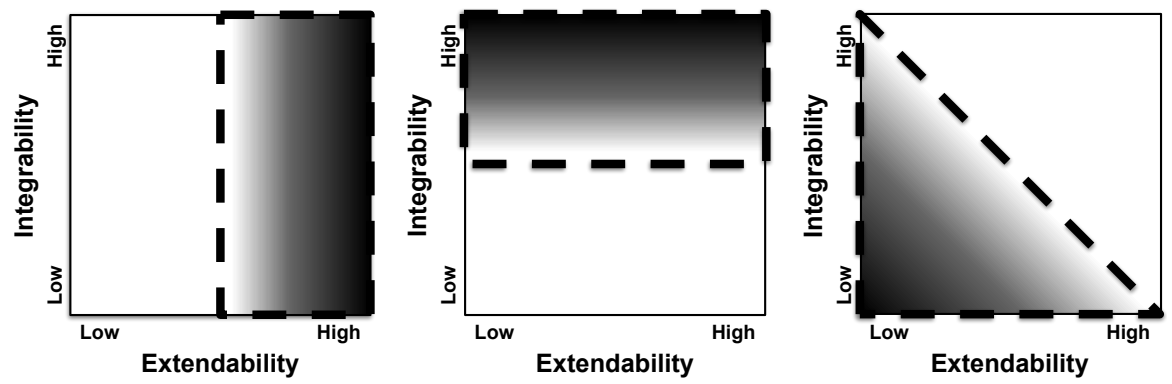

Figure 3.2: If it turns out that human folk psychology is highly extendable (left) or highly integrable (middle) with respect to human-robot interactions, it may generally be relatively easy to interact socially with robots. If, by contrast, extendability and integrability is limited (right), then it may be inherently difficult for humans to interact socially with robots. 


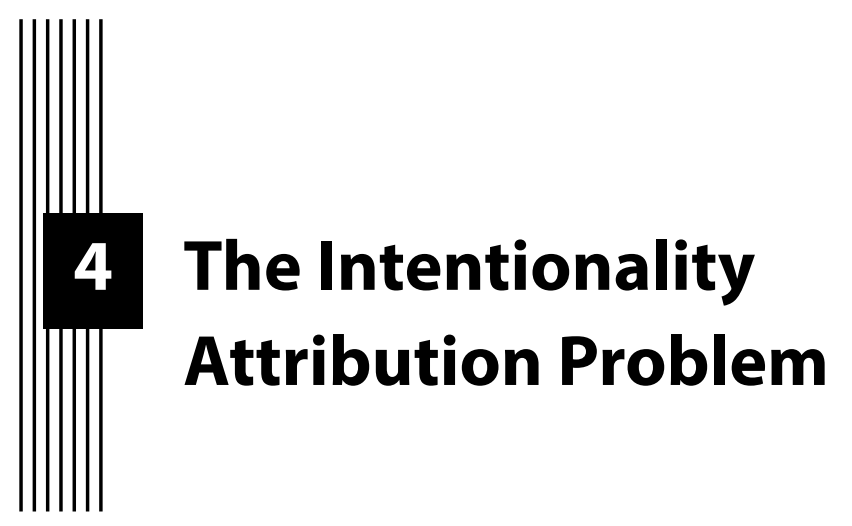

This chapter analyses the problem of attributing intentional states to robots. It is proposed that successful intentional prediction of robot behavior depends on making behavior-congruent attributions (Section 4.1). It is argued that the problem can be broken down into the respective problems of attributing beliefs and desires to robots (Section 4.2). Furthermore, it is argued that attributing perceptual beliefs to robots is a particularly challenging aspect of the more general belief and intentionality attribution problems (Section 4.3).

\subsection{Behavioral Congruency}

A person's understanding of a robotic system from the point of view of the intentional stance can be said to be "good" if the attributed intentional states are conducive to predicting the behavior of the robot and "poor" if they give rise to misguided predictions. Henceforth, the "good" type of attributions will be referred to as behavior-congruent and the "poor" attributions will be referred to as behavior-incongruent. This terminology is intended to be applicable in the analysis of attribution to humans as well as non-human agents that do not necessarily really have intentional states, such as robots, nation states, and fictional characters. When, for example, we see Donald Duck angrily chasing chipmunks Chip and Dale because they are stealing his popcorn, we know that Donald, Chip, and Dale do not really have mental states, but we attribute their behavior to mental states nevertheless (see Paper III), and we do 
so more or less successfully in the sense that our ascriptions of specific intentional states may be more or less conducive to predicting their behavior (i.e., they can be behavior-congruent or not). In the context of human-robot interaction, a person's understanding of a robot as an intentional agent can have real-world consequences. For example, mistakenly thinking that a self-driving car has seen me and therefore knows where I am can be detrimental to both predicting the car's behavior and taking appropriate action (and can have disastrous interaction outcomes as a consequence). Hence, the predictability and interactability of robotic systems depends on people's ability to solve what I call the intentionality attribution problem in human-robot interaction (see Paper IV): the problem of attributing behavior-congruent intentional states to robots.

\subsection{Subproblems}

The intentionality attribution problem can be broken down according to the two main, primitive ${ }^{1}$ types of intentional states that are conducive to predicting and explaining behavior: beliefs and desires (see Figure 4.1). The belief attribution problem is the problem of understanding (attributing) what a robot knows or believes (including false beliefs). The desire attribution problem is the problem of understanding what a robot wants (or does not want). These two problems are distinct insofar as their solution may depend on different types of considerations about the robot in question. For example, figuring out what a robot knows about objects and events in the environment might involve considerations about its perceptual capabilities (e.g., what it can see or hear). Figuring out what it wants, by contrast, might involve considerations about its purpose or role in the environment in which it operates. The two problems are also interrelated to some extent, because what an agent wants (to do) in a given situation may depend on what the agent believes is the case and vice versa (see Paper IV). For example, a robot's beliefs about the immediate environment (e.g., there is a speck of dust under the table) might cause it to want to interact with it in specific ways (e.g., to clean that speck of dust) - perhaps on account of one of its more general desires (e.g., to keep the house clean). Conversely, a cleaning robot might be expected to be able to form beliefs (e.g., about specs of dust in its vicinity) that are relevant to its desire to clean.

According to Dennett's model (Dennett, 1971), three things must be considered when predicting or explaining behavior based on the intentional stance: what the agent wants, what it believes (including any false beliefs), and any constraints on what it can do in the current situation (see Figure 4.2, right group of arrows). For example, predicting a chess-playing computer's next move might involve considering what the best or most rational move would be given the goals and common strategies of chess; what

${ }^{1}$ Beliefs and desires are primitive in the sense that other intentional states (e.g., intentions; Malle \& Knobe, 1997) are intuitively understood as presupposing their existence. 


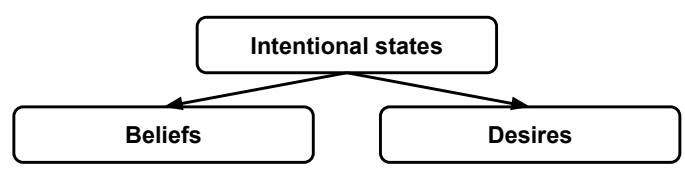

Figure 4.1: The intentionality attribution problem can be broken down according to two primitive intentional states: beliefs and desires.

the computer is likely to believe about, for example, one's own ability to see four moves ahead or one's weakness for knight-bishop exchanges; and the constraints dictated by the rules of chess (Dennett, 1971). However, Dennett's model does not directly or explicitly account for the fact that, as argued in Section 3.2, attributing the appropriate (i.e., behavior-congruent) intentional states is an underdetermined problem that can only be solved by relying on folk-psychological assumptions about the agent in question (see Figure 4.2, left group of arrows).

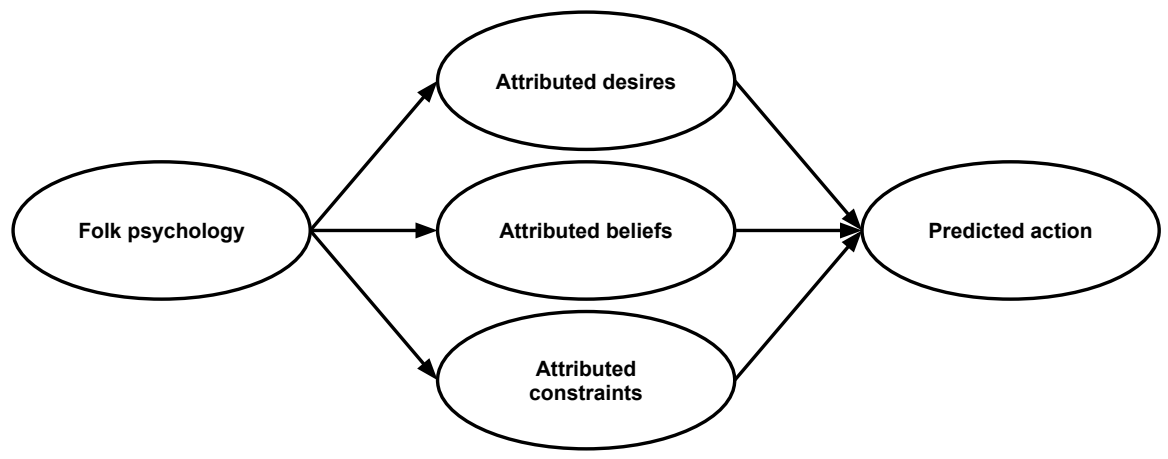

Figure 4.2: Intentional prediction is based on attributions of beliefs, desires, and constraints that are, in turn, based on folk-psychological assumptions about the agent.

To illustrate how folk-psychological assumptions might form a basis for attributing specific intentional states to a robot and predicting its actions, consider the example of a person approached by a robot in a restaurant. Knowing that restaurants typically have waiters and that waiters have certain common characteristics in terms of appearance, behavior, equipment, and so on, a person might assume the robot is fulfilling the role of a waiter, i.e., that the robot is a "waiter robot". Also knowing that waiters are likely to want to serve customers and to be well versed in the offerings of the restaurant, the person might predict that the robot will (be able to) provide relevant answers to specific questions about items on the menu, such as "What's today's special?" (see Figure 4.3). This is an example in which the application of folk-psychological knowledge about humans is extended for the purpose of predicting the behavior of a robot (cf. Section 3.3). 


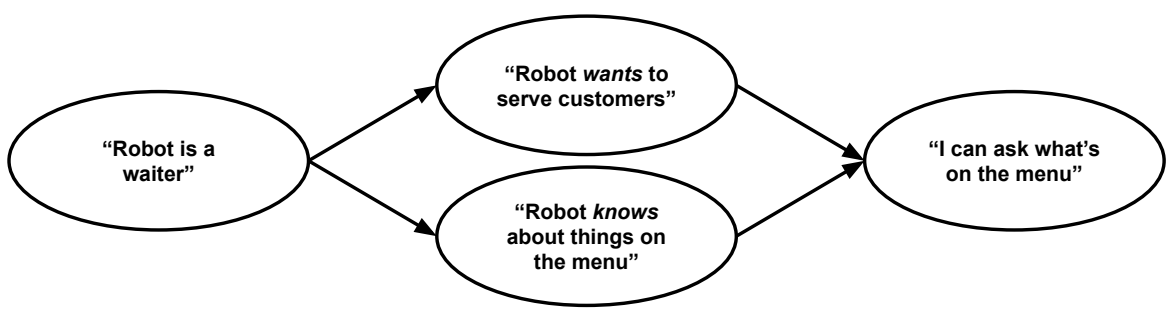

Figure 4.3: Folk psychology in (human-robot inter)action: a person predicts that a robot recognized as a waiter will (be able to) provide relevant answers to questions about items on a restaurant menu.

The belief and desire attribution problems are equally important for the purpose of predicting the behavior of robots, and equally important to address from scientific and practical perspectives. From a scientific perspective, identifying the folkpsychological assumptions that guide people's interactions with robots - including those that mislead - leads to a better understanding of the scope and limits of people's ability to interact with robots by treating them as intentional agents, particularly as it addresses the extendability and integrability questions formulated in Section 3.3. From a practical perspective, designers of human-robot interactions may use this knowledge to improve human-robot interaction through design that facilitates the attribution of behavior-congruent intentional states. This thesis does not engage empirically with every aspect of the overarching intentionality attribution problem, rather it focuses on a particular aspect of the belief attribution problem that, as argued in Paper IV and indicated by the results of the study reported in Paper V, is a particularly significant, difficult, and unique problem in human-robot interactions: the perceptual belief attribution problem (see Figure 4.4). This problem is introduced in the following section.

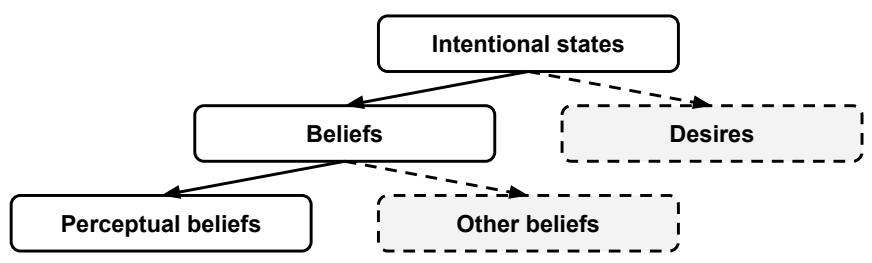

Figure 4.4: A robot's perceptual beliefs are constituted by what the robot knows (or believes) about objects and events in the world based on its perception. The diagram also illustrates the relationships between three problems that this thesis addresses: the intentionality attribution problem, the belief attribution problem, and the perceptual belief problem. Adapted from Paper IV. 


\subsection{The Perceptual Belief Problem ${ }^{2}$}

A significant limitation in the way that the belief attribution problem has been approached thus far is that very little attention has been given to how people estimate robots' perceptual beliefs, i.e., what robots know (or believe) about objects and events in the world based on their perception. The ability to estimate what a co-present agent knows about a shared environment is a fundamental interactive skill that is essential in interactions with robots (as physically co-present interactive objects). In the following, I explain why people's understanding of robots' perceptual beliefs is subject to a significant limitation that negatively affects the predictability and explainability of robotic systems.

The physical embodiment of robots allows humans and robots to share the same physical environment. Furthermore, shared knowledge can be facilitated by co-presence and mutual observation. Being co-present with one another, humans and robots can, in principle, see, hear, and interact with what the other is interacting with, allowing them to, among other things, anticipate each other's actions in relation to objects and events in a shared environment. However, estimating another person's knowledge based on co-presence presupposes that one is able to reliably infer the other's beliefs about objects and events in the environment ${ }^{3}$. In cases of human-human interaction, this is, more often than not, unproblematic - people are generally safe in assuming that another person who is looking at an object is also attending to it, and will draw similar conclusions about it (Clark \& Marshall, 1981). However, in human-robot interactions such assumptions are precarious due to the fact that the mechanisms by which humans and robots perceive and understand the world differ considerably. While research in embodied AI and cognitive science (e.g., Brooks, 1991; Clark, 1998; Ziemke \& Sharkey, 2001) has acknowledged the fact that any robot necessarily has a different perceptual world - or Umwelt (von Uexküll, 1982) - than humans, the implications for HRI have received relatively little attention so far. What I call the perceptual belief attribution problem in social robotics/HRI - or perceptual belief problem for short - is this: How can people understand what robots know (and do not know) about the shared physical environment?

One seemingly straightforward way of solving the perceptual belief problem might be to rely on the extendability of folk psychology (cf. Section 3.3) and build robots with similar perception and cognition as humans, so that people that interact with a robot can simply assume it to have beliefs about the environment that are sufficiently

\footnotetext{
${ }^{2}$ Most of this section appeared in similar form in Paper IV.

${ }^{3}$ Note that I do not suggest that beliefs are necessarily are propositional or that belief inference is necessarily active in the sense of being conscious or effortful. More specifically, intuitive or non-inferential processes (e.g., mental simulation, see R. Gordon, 1992) may also play an important role in people's understanding of the intentional states of robots.
} 
similar to what a person would typically have in the given situation ${ }^{4}$. This solution is, however, implausible in the foreseeable future due to the fact that, as discussed in Section 2.3, the perceptual and cognitive mechanisms that govern belief formation in humans are largely unknown and cannot presently be implemented in a machine. Hence, until such a solution is possible (if possible and feasible at all), people encountering and interacting with robots will face the problem of inferring their ability to perceive and understand the environment without relying on the assumption that it is highly similar to one's own ability.

To highlight the significance of the perceptual belief problem, it is useful to consider how central the assumption of similar perception and cognition is in many types of interpersonal interactions. When, for example, we encounter a road vehicle in traffic, the driver's beliefs about the ongoing traffic situation often cannot be easily inferred directly based on information in the shared environment. Instead, we must assume the driver to believe the things a driver would typically believe in the given situation. When another vehicle drives straight toward us in our lane on a country road while passing another vehicle, we trust with high probability - high enough for us not to panic, brake, or drive off the road - that the other driver is aware of our presence and will return to their own lane as soon as the passing is complete. Arguably, it is our very strongly held assumption that others have similar perception and cognition to ourselves that allows these interactions to take place.

For a less dramatic but more commonplace example of reliance on similar perception and cognition, consider the use of definite reference, that is, linguistic expressions used to refer to a definitely identifiable referent, such as when referring to this candle. As argued by Clark and Marshall (1981), such linguistic behavior presupposes evidence of triple co-presence - of events in which the speaker, addressee, and target object (the candle) are co-present. However, mere co-presence is not enough for definite reference to work. The speaker must be able to count on the addressee's awareness of the object. The reason that people can make such assumptions about one another, with a high degree of predictive success, may be that the mechanisms that underlie human perception and cognition are sufficiently similar across individuals in the human population. Because of this similarity, people are able to estimate what others know about the environment based on what they themselves know (Nickerson, 1999; Tamir \& Mitchell, 2013). However, in human-robot interactions, because speakers often cannot count on robots to be aware of objects and events in the environment, the use of proper nouns and spatial deixis (here, there, this, that, and so on) as communicative devices becomes significantly limited.

\footnotetext{
${ }^{4}$ This might also require that robots are built with the appropriate external features to communicate human-like capabilities, such as eye-gaze directionality (Admoni \& Scassellati, 2017; Meltzoff, Brooks, Shon, \& Rao, 2010).
} 
Perhaps more serious and fundamental than any communication issue is the fact that the perceptual belief problem makes it difficult for people to predict how robots will behave in response to events that transpire in the environment. This, in turn, has a compounding effect on people's uncertainty about their own future states and actions. For example, if it is unclear whether a robot is aware of the presence and attributes of an object that is on a collision course with it, it will be difficult to predict whether the robot will act to avoid this collision, and therefore it will likely also be difficult to decide whether to intervene in the robot's execution of its planned actions to prevent an accident that might never happen anyway. In interpersonal interactions, people constantly keep track of others' perceptual beliefs (Kovács, Téglás, \& Endress, 2010) and act to minimize discrepancies between the beliefs of others and themselves when it is relevant within the context of the given situation (e.g., through explaining their own behavior or asking for explanations of others'; Malle, 2006). However, such "interaction-managing actions" are impossible if the beliefs of the robot cannot be tracked in the first place. The perceptual belief problem thus causes difficulty not only in predicting and explaining robot behavior but in managing interactions with robots. This might also negatively impact people's trust in robotic systems (e.g., Hancock et al., 2011), thereby potentially reducing user acceptance (de Graaf \& Allouch, 2013; Gaudiello, Zibetti, Lefort, Chetouani, \& Ivaldi, 2016).

The perceptual belief problem is largely unique to social robotics. It does not appear in cases of human-robot interaction where people interacting with a robot do not have to consider what the robot knows in order to predict and explain its behavior. For example, the owner of a lawnmower robot typically does not have to reason about what the robot knows in order to use it and avoid collisions. The perceptual belief problem is not (or is much less) present in typical human-computer interactions, such as in interactions with chess-playing computers or screen-confined AI applications, because computers, in contrast to social robots, do not have to deal with the physical environment in a comprehensive way (i.e., computers' perceptual beliefs, if they have any at all, tend to be simple, well-calibrated, and small in number, such as the positions of pieces on a chessboard). The problem generally does not arise in human-human interactions either, because people are able to estimate each other's perceptual beliefs with high precision, based on the assumption that others generally believe the same things about the environment as themselves (Clark \& Marshall, 1981; Tamir \& Mitchell, 2013) (which holds true because of the underlying similarity in perceptual and cognitive mechanisms amongst individuals in the human population). The problem might be present to some degree in human-animal interactions. However, the fact that animals have (partly shared) evolutionary and, to some extent, cultural histories that constrain their intra-species perception and cognition makes it generally easier to infer the perceptual beliefs of an animal than of a robot, which could be endowed with virtually any perceptual and cognitive mechanisms technically avail- 
able. For example, people know relatively well what to expect and what not to expect of dogs or cats, but currently that is simply not the case for robots.

In sum, the perceptual belief problem is a largely unique problem in social robotics that adversely affects the predictability and explainability of robotic systems. In particular, people's need to treat robots as intentional systems, combined with the inability to judge what a robot knows about a shared environment, gives rise to serious problems with interaction, such as the inability to communicate about objects and events in the environment and uncertainty about how to act in response to events that transpire in the environment. It might also be worth noting that belief inference is fundamental to the inference of other types of psychological states, including intentions (Malle \& Knobe, 1997), emotions (e.g., as in "it is upset because it thinks that I am not paying attention"), and desires (Csibra \& Gergely, 2007). Because of this interdependence, inference of other psychological states (possibly including nonintentional ones) may also be affected by the perceptual belief problem. 


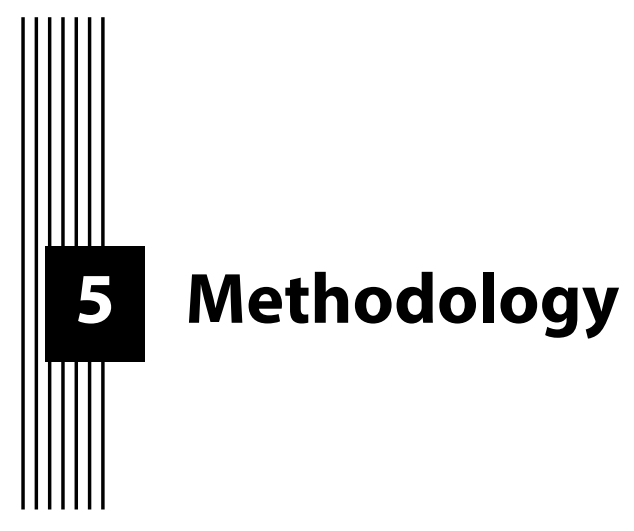

This chapter proposes a general research methodology for studying the intentionality attribution problem. It is proposed, as general methodological criteria, that this requires methods to observe the behavioral effects of people's understanding of robots as intentional agents (Section 5.1), and to - on the basis of such observation - reliably infer the attribution of specific intentional states (Section 5.2) and their underlying folk-psychological causes (Section 5.3). Methods that satisfy these criteria are discussed. Furthermore, the application of the proposed methodology is illustrated in the context of studying the perceptual belief problem (Section 5.4).

\subsection{Observation of Behavioral Effects}

As argued in the previous two chapters, people solve the intentionality attribution problem(s) of attributing behavior-congruent intentional states to robots by tacitly applying their folk-psychological knowledge to the situation at hand. Therefore, it is important that people's folk-psychological assumptions, and the conditions under which they give rise to behavior-(in)congruent attributions, are studied in detail. However, studying the attribution of intentional states to robots, including the causes of such attributions, is complicated considering that attribution processes - just like intentional states (cf. Section 2.2) - are cognitive and "internal" and therefore can only be inferred based on evidence of the "external" behavioral effects that they have (Figure 5.1). 


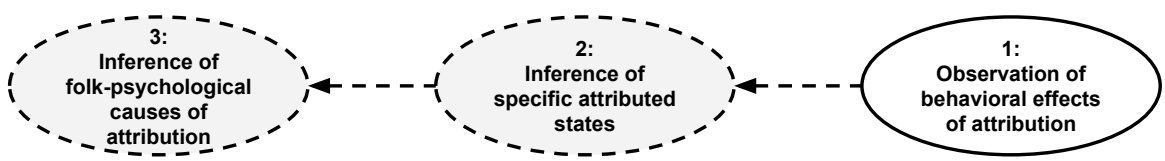

Figure 5.1: Studying the intentionality attribution problem(s) requires methods to observe the behavioral effects of people's understanding of robots as intentional agents.

Attribution of intentional states arguably has two distinct primary behavioral effects: it affects how people predict behavior, and it also affects how people explain their own behavior and that of others. Hence, there are at least two approaches to the study of these behavioral effects (which may be complementary): observation of people's explanations of robot behavior (e.g., de Graaf \& Malle, 2019) and observation of people's predictions of robot behavior (e.g., Levin et al., 2013).

Studying attribution based on explanation has the advantage that explanation data is relatively accessible but also has the significant limitation that verbal accounts (i.e., self-reports) are not necessarily a good reflection of how people interact with others. This is because people do not necessarily have introspective access to the causes of their own behavior. There is significant evidence that people's explanations of their own and others' actions are sometimes false or misguided reconstructions of the actual behavioral cause (Nisbett \& Wilson, 1977; Greenwald \& Banaji, 1995). More generally, self-reported data are subject to a number of well-documented biases (Podsakoff \& Organ, 1986; Paulhus \& Vazire, 2007; Donaldson \& Grant-Vallone, 2002), such as social desirability bias, i.e., the tendency of research participants to respond verbally in a way that makes them look as good as possible (Moorman \& Podsakoff, 1992) ${ }^{1}$. As described in Paper VI, several researchers have, for these and other reasons, cautioned against relying on verbal measures to study human attribution of intentional states (and other mental states) to robots.

Another concern with relying on explanation is that, whereas explanations may provide valuable insights about a person's understanding of a robot as having particular (attributed) intentional states, data derived from explanations are not well-suited for the assessment of behavioral congruency (i.e., how well attributed intentional states correspond to the observable behavior of the robot, cf. Section 4.1). In an experimental context, predictions can be set up so that they can be either correct or incorrect (see subsequent sections). Explanations, in contrast, typically have several (or a potentially infinite number of) equally valid alternatives, and no simple way of determining how descriptive or accurate the explanation is with respect to the explained behavior. For this reason, studying how people predict the behavior of robots is important to the assessment of behavioral congruency.

\footnotetext{
${ }^{1}$ It should be noted that, despite these methodological limitations, a majority of studies on mental state attribution to robots rely on self-report measures such as questionnaires (cf. Paper VI)
} 
Studying attribution based on verbal prediction has been successful in the context of, for example, experimental studies that employ verbal false-belief tasks to study theory of mind development (Baron-Cohen et al., 1985; Wimmer \& Perner, 1983; Wellman, Cross, \& Watson, 2001). However, similar methodological limitations apply to verbal predictions due to the fact that they appeal to deliberate thought processes. In addition to these general concerns, questions about the behavior and minds of robots may be ambiguously open to interpretation with regard to the reality of the intentional states of robots, meaning that answers to such questions may vary depending on the interpretation of the respondent (Thellman \& Ziemke, 2019). Moreover, verbal measures employed to study belief attribution in the context of experimental research on theory of mind produce results that are consistently different from those produced by non-verbal measures (e.g., Schneider, Slaughter, \& Dux, 2015; Clements \& Perner, 1994). This also seems to be the case in the human-robot interaction context (Thellman, Giagtzidou, Silvervarg, \& Ziemke, 2020; Spatola \& Wudarczyk, 2020), where, for instance, Spatola and Wudarczyk (2020) found that the non-verbal measure employed in their study was a better predictor of a future behavior toward the robot than explicit measures.

Taken together, the methodological limitations of verbal measures suggest that nonverbal measures of people's predictions of robot behavior are appropriate for studying the behavioral effects of people's understanding of robots as intentional agents. Moreover, observing people's predictions of robot behavior offers the possibility of assessing the behavioral congruency of attributed intentional states, which makes prediction, rather than explanation, the preferable type of behavioral effect of intentional state attribution as a target of study. A concrete example of a non-verbal measure of robot behavior prediction that employs the proposed methodological approach will be described in Section 5.4. We first turn to the issue of how attributed intentional states and their associated folk-psychological causes can be inferred based on observations of people's predictions of robot behavior.

\subsection{Inference of Attributed Intentional States}

Studying the intentionality attribution problem requires methods to reliably infer the attribution of specific intentional states (Figure 5.2). As previously mentioned, prediction-based measures of intentional state attribution have been successfully used for this purpose, in the context of theory of mind research, in the form of various false-belief task paradigms (Wellman et al., 2001). The method I propose is a modified version of the standard "location-change" false-belief task (Baron-Cohen et al., 1985; Wimmer \& Perner, 1983).

When faced with a standard false-belief task, an experimental participant is made aware that an agent has a false belief about some state of affairs (e.g., by showing that 


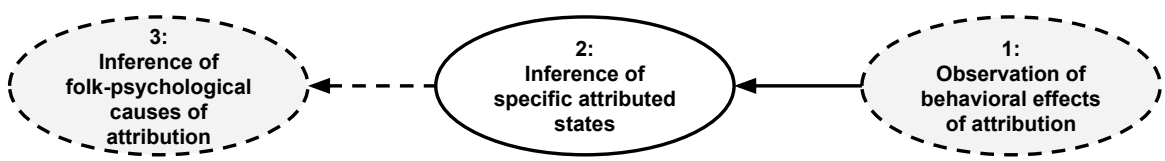

Figure 5.2: Studying the intentionality attribution problem(s) requires methods to reliably infer the attribution of specific intentional states.

an object that belongs to the agent has been displaced in its absence) and is then asked to predict how the agent will behave given its false belief (e.g., by asking where the agent will look for the object when returning to retrieve it). If, for example, in the case of the classical "Sally-Anne" version of the task (Baron-Cohen et al., 1985), experimental subjects think that Sally holds a false belief about the location of an object (e.g., having observed the object being displaced by Anne in Sally's absence), then they are likely to predict that Sally will look for the object in the wrong place. If, on the other hand, they think Sally has a true belief (e.g., having observed that Sally is aware of the displacement), then they are likely to predict that Sally will look for the object in the right place. That means that the subjects' predictions of Sally's behavior implicitly tell us something about their beliefs about Sally's beliefs (cf. Figure 5.3).

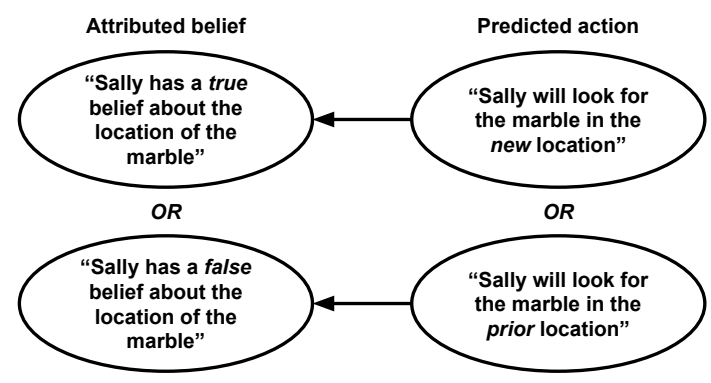

Figure 5.3: In the standard "location-change" false-belief task, study participants' attribution of true or false belief is inferred based on how they predict an agent will act in a specific situation.

\subsection{Inference of Folk-Psychological Causes}

The standard false-belief task has been used previously to study belief attribution to robots (e.g., Banks, 2020; Thellman, Silvervarg, \& Ziemke, 2020). However, the experimental logic of the standard false-belief task methodology does not accommodate studying the causes of (or reasons behind) people's attributions, i.e., why people attribute the specific intentional states that they do (cf. Figure 5.4). The reason for this is that the protagonist or "false believer" in standard false-belief task scenarios is typically depicted as being absent or distracted from the event that leads to the false belief (e.g., displacement of object). Hence, because the protagonists' ignorance is 
pre-given via the task description, considerations about why the protagonist formed a false belief are taken out of the equation. I therefore propose a modified version of the standard false-belief task that accommodates such considerations and make them empirically accessible.

In the modified version of the false-belief task, the protagonist's intentional states (e.g., what the protagonist wants or knows) are instead made contingent upon how the protagonist relates to the situation at hand. Because these situational factors are not part of the task description, the experimental participant must rely on folk-psychological assumptions about the protagonist to attribute the appropriate intentional state(s). In the following section, I provide a concrete example of an experimental setup that employs the proposed experimental logic.

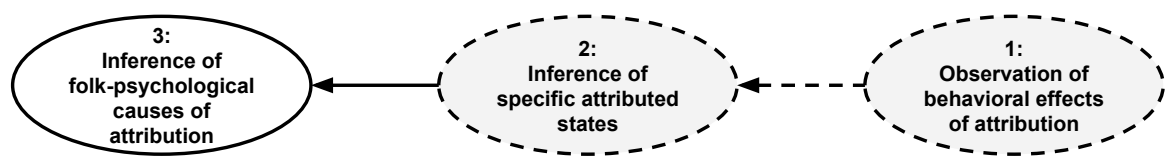

Figure 5.4: Studying the intentionality attribution problem(s) requires methods to reliably infer the folk-psychological causes (reasons) of the attribution of specific intentional states.

\subsection{Application}

The perceptual belief problem is the problem of how to attribute appropriate perceptual beliefs to robots (see Section 4.3). To solve this problem, a person must have a reasonably accurate idea about a robot's perceptual and cognitive capabilities. Because such capabilities are not directly observable but must rather be inferred, there is always an element of uncertainty inherent in figuring out what a robot can or cannot perceive in the environment. For this reason, folk-psychological assumptions (e.g., about what a robot can or cannot see or hear) must be relied on to solve the perceptual belief problem (Figure 5.5).

To infer a person's attribution of specific perceptual beliefs to a robot, an experimental scenario is constructed in which the robot's future action depends on its perceptual belief about some relevant state of affairs, $x$, in the environment (e.g., the current location of an object; see Figure 5.6) and where that perceptual belief is, in turn, contingent upon the robot's ability to perceive an event, $y$, that affects the status of its belief as true or false (e.g., a relocation of the object). The person is then exposed to the scenario and is either explicitly asked to predict the robot's action or, as was done in Paper V, the person's predictions are inferred via anticipatory gaze behavior measured using eye-tracking technology. The scenario is set up so that the robot must decide to act in one of two ways: the robot can either act in a manner consistent with it having 


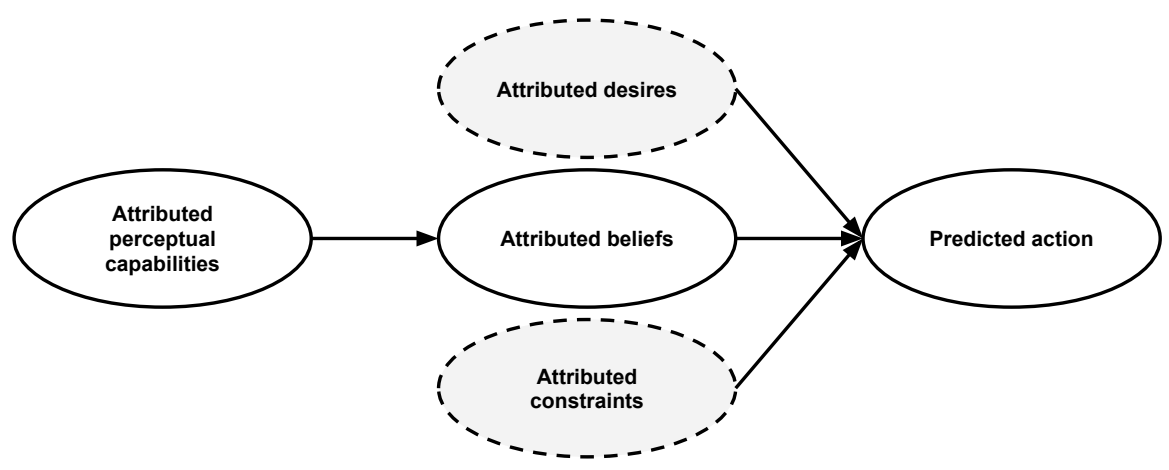

Figure 5.5: Attribution of perceptual belief is based on folk-psychological considerations about the agent's perceptual and cognitive capabilities.

a true belief about $x$ (e.g., point out the true location of the object) or act in a manner consistent with it having a false belief about $x$ (e.g., point out the false location of the object). If the person makes the former prediction, it means that the person thinks the robot has a true belief about $x$ based on an assumption that the robot was capable of perceiving $y$ (i.e., the event that affected its belief about $x$ ). If the person makes the latter prediction, it means that the person thinks the robot has a false belief about $x$ based on an assumption that it was incapable of perceiving $y$. Hence, the person's assumptions about the perceptual capability of the robot can be inferred based on how they predict the robot will act in the experimental scenario. Using this approach, it is possible to observe whether the person's assumptions about the robot's perceptual capabilities gives rise to a behavior-congruent (if prediction is correct) or behaviorincongruent (if prediction is incorrect) attribution of perceptual belief. This means that the method can be used to identify circumstances in which people struggle to attribute appropriate intentional states to robots, which opens up for the possibility of improving human-robot interactions through design that facilitates the attribution of behavior-congruent intentional states. 


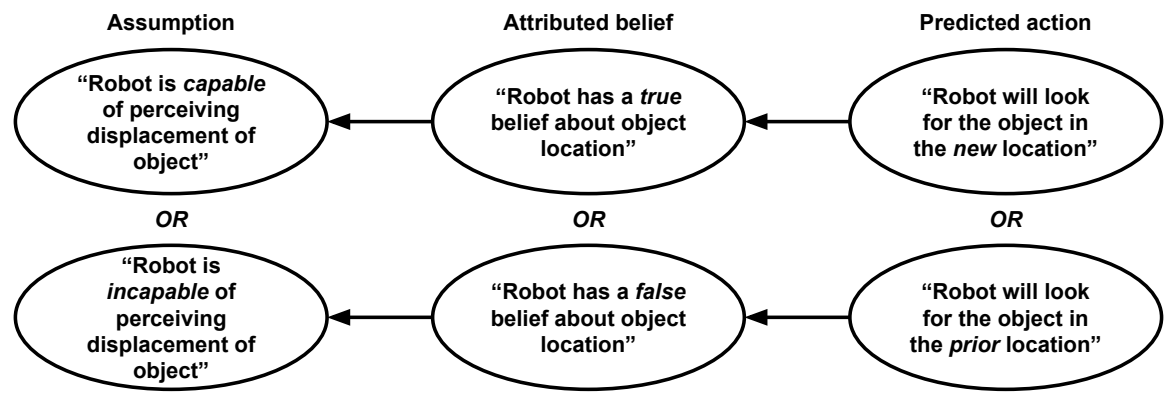

Figure 5.6: In the proposed modified false-belief task, study participants' folkpsychological assumptions about a robot are inferred based on how they predict the robot will act in a specific situation. 


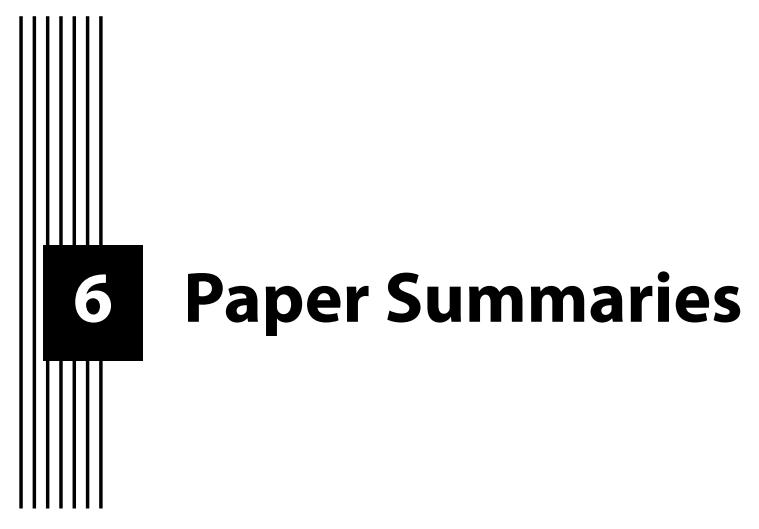

This chapter contains summaries of the six publications included in this compilation thesis (Sections 6.1-6.6). Each summary serves as a comprehensive overview of the respective paper's main contributions to the thesis project (for increased readability, each paper's most important contribution is highlighted in bold font). See Table 6.1 for an overview of the types of contributions (theoretical, methodological, and empirical) of each paper.

Table 6.1: The primary type(s) of contribution of each paper.

\begin{tabular}{lccc}
\hline & Theoretical & Methodological & Empirical \\
\hline Paper I & $\checkmark$ & & $\checkmark$ \\
Paper II & & & $\checkmark$ \\
Paper III & $\checkmark$ & & \\
Paper IV & $\checkmark$ & $\checkmark$ & \\
Paper V & & $(\sqrt{ })$ & $\checkmark$ \\
Paper VI & $(\sqrt{ })$ & & \\
\hline
\end{tabular}




\subsection{Paper I}

Thellman, S., Silvervarg, A., \& Ziemke, T. (2017). Folk-psychological interpretation of human vs. humanoid robot behavior: Exploring the intentional stance toward robots. Frontiers in Psychology, 8, 1962.

Paper I reports on an experimental study comparing people's tendencies to attribute behavior to underlying intentional states when the behavior is enacted by a human versus by a humanoid robot (see Figure 6.1). It is argued that because people rely on folk-psychological knowledge when judging behavior, such knowledge needs to be taken into consideration in the design of robots and other autonomous systems that are expected to interact socially with people (this basic argument is elaborated in Chapters 2-3 in the thesis). The results of the study show that study participants attributed the same degree of intentionality and employed a similar folk-conceptual framework when they judged the behavior of the robot as when they judged the corresponding human behavior. This suggests that people apply their pre-existing folkpsychological understanding of others, which is based primarily on sociocultural experiences with humans, when judging the behavior of humanoid robots based on the intentional stance (cf. the "extendability question" in Section 3.3).

The author of this thesis is the primary contributor in all research activities associated with Paper I, including conceptualization, methodology, data collection, data analysis, and writing (drafting, reviewing, and editing).
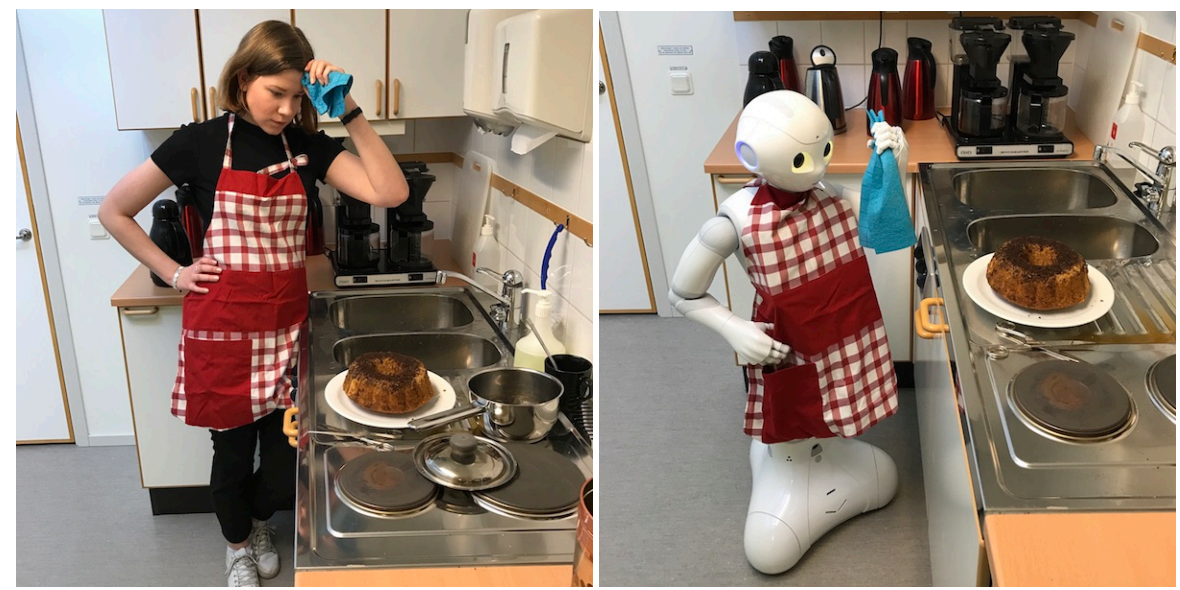

Figure 6.1: "Ellis is frustrated over cooking": behavior description and images from the stimulus materials presented to participants in the study reported in Paper I. 


\subsection{Paper II}

Petrovych, V., Thellman, S., \& Ziemke, T. (2018). Human interpretation of goal-directed autonomous car behavior. In The 40th Annual Cognitive Science Society Meeting, July 25-28, Madison, Wisconsin, USA (pp. 2235-2240). Cognitive Science Society.

Paper II is a conceptual replication of the experimental study in Paper I that focuses on intentional state attribution to a different type of robotic system, an autonomous or "driverless" vehicle (see Figure 6.2). Vehicular robots differ from humanoid robots in that they (mostly) lack human appearance. The findings of Paper II were similar to the findings of Paper I: study participants' attributions were largely similar in the robot and human conditions of the experiment. This suggests that people interpret a wide range of robotic systems as intentional agents.

The author of this thesis shared co-first authorship of Paper II and is, together with the other co-first author, the primary contributor in all research activities associated with Paper II, including conceptualization, methodology, data collection, data analysis, and writing (drafting, reviewing, and editing).
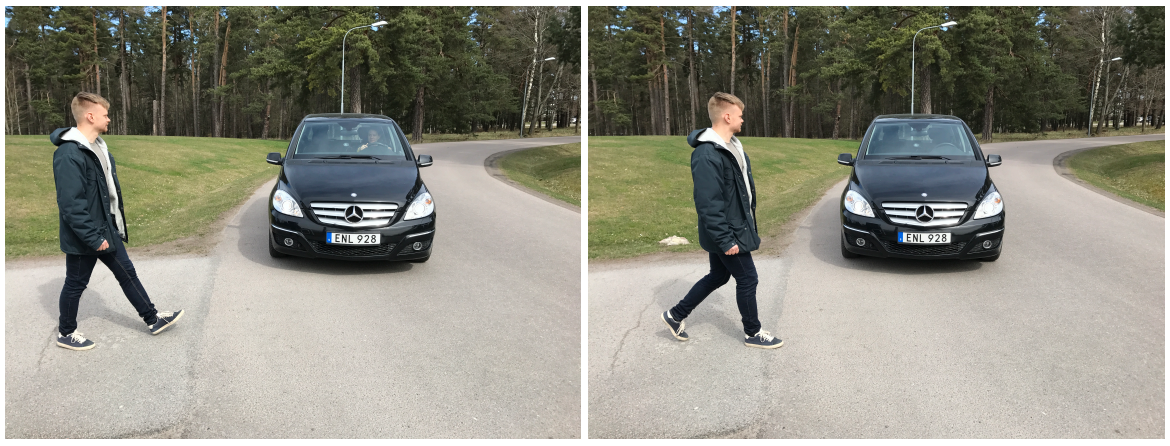

Figure 6.2: “The car stops too late at the unmarked crossing": behavior description and images from the stimulus materials presented to participants in the study reported in Paper II. Note that the car in the left image has a human driver, whereas the car in the right image does not.

\subsection{Paper III}

Thellman, S., \& Ziemke, T. (2019). The intentional stance toward robots: conceptual and methodological considerations. In The 41 st Annual Conference of the Cognitive Science Society, July 24-26, Montreal, Canada (pp. 1097-1103). Cognitive Science Society 
Paper III argues that it is important to study how people's understanding of robots as intentional agents affects how they interact with them. It is argued that, as a distinct research question, this question - referred to in the paper as the "intentional stance question" - is often confused with overlapping but different questions, such as whether robots have minds, whether people think that robots have minds, and what kinds of mental states people ascribe to robots. It also provides conceptual clarifications surrounding the related notions of "folk psychology", "theory of mind", and "intentional stance" and the relevance of these terms to human-robot interaction. These conceptual considerations are elaborated in Chapter 3 in this thesis.

Paper III also outlines methodological criteria for studying the intentional stance question empirically. Specifically, it is proposed that "if one wants to investigate whether the intentional stance is useful as an interpretative framework for predicting robot behavior, then one must, at the very least, measure people's predictions of behavior and ensure that those predictions stem from specific attributed mental states". It also points out various limitations related to the use of verbal measures to study attribution of intentional (and other mental) states to robots. Paper III thereby lays out the foundation for the methodology that is further developed in Paper IV, described in Chapter 5 in this thesis, and employed in Paper V.

The author of this thesis is the primary contributor in all research activities associated with Paper III, including conceptualization and writing (drafting, reviewing, and editing).

\subsection{Paper IV}

Thellman, S., \& Ziemke, T. (2021). The perceptual belief problem: Why explainability is a tough challenge in social robotics. ACM Transactions on Human-Robot Interaction, 10(3). doi:10.1145/3461781.

Paper IV is a position paper that presents and analyzes the intentionality attribution problem, i.e., the problem of attributing intentional states that are conducive to predicting the behavior of robots (i.e., what is referred to in Chapter 4 as"behaviorcongruent" attributions/states). It argues that it is particularly important to study how people can understand what robots know (and do not know) about the shared physical environment given difficulties associated with inferring a robot's perceptual and cognitive capabilities, i.e., the perceptual belief problem in human-robot interaction (see Section 4.3). It also argues that people may in some cases have to adopt the intentional stance toward robots in order to predict their behavior and interact with them. Paper IV provides the foundations for Chapter 4 in the thesis. 
The author of this thesis is the primary contributor in all research activities associated with Paper IV, including conceptualization and writing (drafting, reviewing, and editing).

\subsection{Paper V}

\section{Thellman, S., \& Ziemke, T. (2020). Do you see what I see? Tracking the per- ceptual beliefs of robots. iScience, 23(10), 101625.}

Paper V reports an experimental study of people's attribution of perceptual beliefs to a humanoid robot, based on the methodology developed in Papers III-IV and described in Chapter 5 in this thesis (Figure 6.3 serves to illustrate the experimental logic of the study, but see the paper for details). The results provide empirical validation to some of the central claims in the thesis, including the assertion that the perceptual belief problem is a significant problem in human-robot interaction. The study makes three important contributions by demonstrating:

- A set of circumstances in which study participants predicted the behavior of a robot by treating it as an intentional system (specifically based on perceptual belief ascription).

- Limitations in the extendability of human/animal folk psychology to interactions with robots (cf. Section 3.3) by showing that (1) study participants tended toward the assumption that the robot had human-like perceptual and cognitive capabilities in all of these circumstances and (2) that they, as a consequence of this "anthropocentric" assumption, were unable to reliably predict the behavior of the robot.

- Some degree of integrability of experiences with robots into folk psychology (cf. Section 3.3) by showing that study participants were able to adjust their folkpsychological assumptions about a robot's capabilities over time by observing its interaction with the environment and, as a consequence, were able to improve their ability to predict its behavior and interact with it.

The author of this thesis is the primary contributor in all research activities associated with Paper V, including conceptualization, methodology, data collection, data analysis, and writing (drafting, reviewing, and editing). 

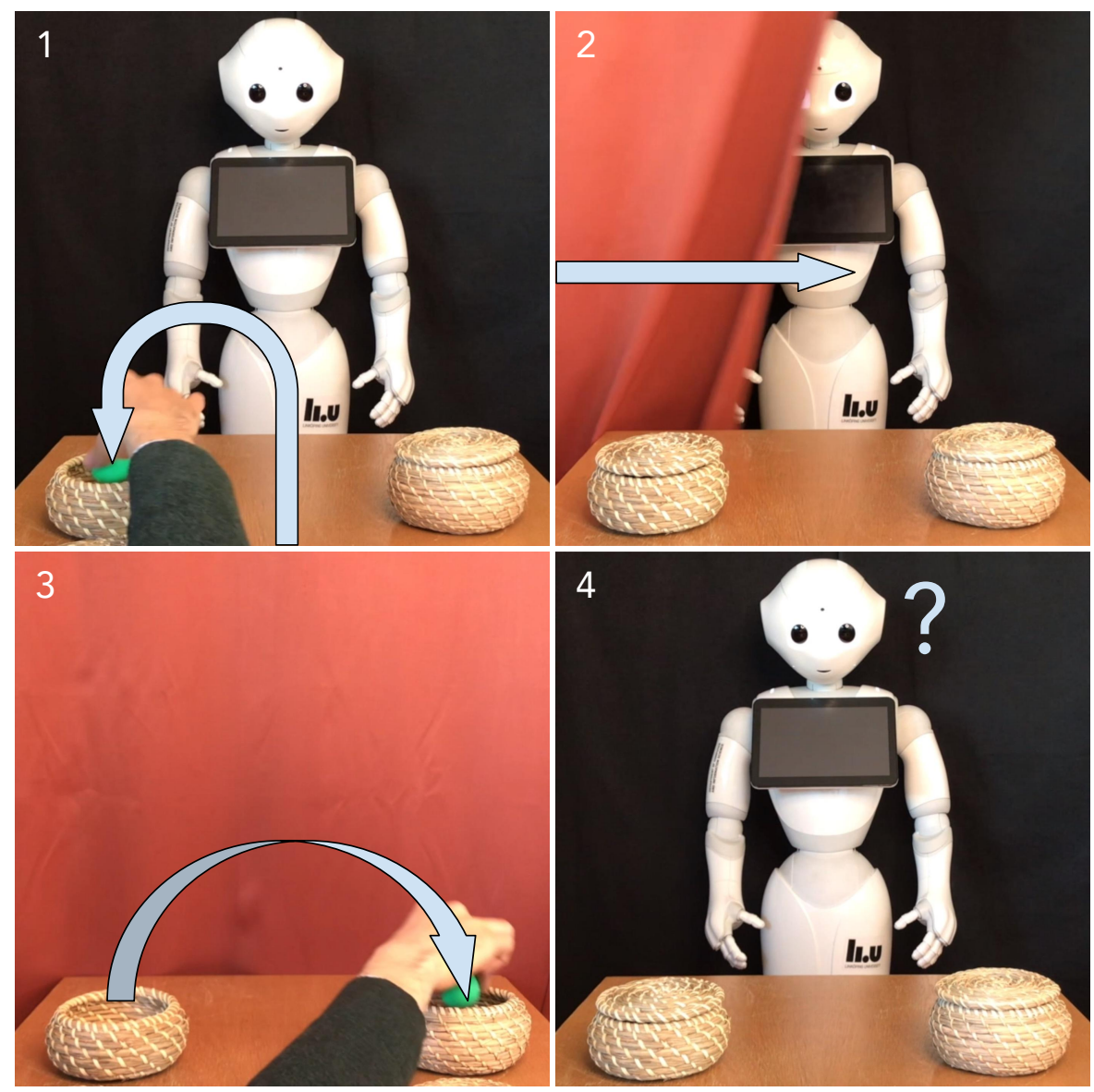

Figure 6.3: Study participants in Paper V watched a video of a ball being placed in one of two baskets in front of a robot (1). An opaque or transparent curtain was pulled in front of the robot (2) and the ball was silently removed from the basket and placed into the other basket (3). The participants then had to judge whether the robot would see the displacement of the ball through the curtain in order to predict which basket the robot will point to when asked about the ball's location (4). This judgment was inferred based on the presence of anticipatory saccades toward the robot's arms that were measured using eye-tracking technology. 


\subsection{Paper VI}

Thellman, S., de Graaf, M., \& Ziemke, T. (in review). Mental state attribution to robots: A systematic review of conceptions, methods, and findings. Submitted to ACM Transactions on Human-Robot Interaction, June 2021.

Paper VI is a systematic literature review ${ }^{1}$ of the conceptions, methods, and findings in the empirical literature surrounding mental state attribution to robots. Importantly for the purposes of the thesis, the results of Paper VI show that very little prior research exists on the topic of people's ability to interact socially with robots by treating them as intentional agents (i.e., the topic of this thesis). More broadly, the review addresses the need for a shared scientific understanding of mental state attribution to robots. This is a topic that has been approached by researchers from a variety of disciplines, which exhibits considerable diversity in terms of how the phenomenon is described and how it is approached from a theoretical and methodological standpoint. Paper VI makes a number of contributions to this end, including the findings that:

- The terminology used to describe mental state attribution to robots is diverse but largely homogenous in usage.

- The tendency to attribute mental states to robots is determined by factors such as the age and motivation of the human as well as the behavior, appearance, and identity of the robot.

- There is a computer $<$ robot $<$ human pattern in the tendency to attribute mental states that appears to be moderated by the presence of socially interactive behavior.

- There are apparent contradictions in the empirical literature that stem from different sources of evidence, including self-reported and non-verbal behavioral or neurological data.

- There are important research gaps in the literature, including with respect to how people's attributions of mental state affect how they interact with robots (i.e., the topic addressed in this thesis).

The author of this thesis is the primary contributor in all research activities associated with Paper VI, including conceptualization, data collection, data analysis, and writing (drafting, reviewing, and editing).

${ }^{1}$ A systematic literature review employs a pre-specified and auditable methodology for the purpose of systematically identifying and appraising all available evidence (Kitchenham \& Charters, 2007). 


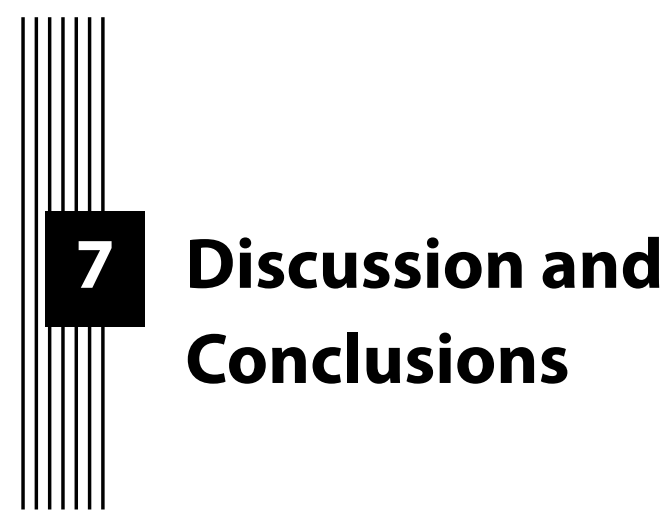

This chapter provides a summary (Section 7.1), and discusses the limitations (Section 7.2) as well as the broader implications of the thesis (Section 7.3).

\subsection{Summary}

Robots that can engage in social interactions with humans are a promising technology. The ability of robots to interact socially with humans is, however, currently significantly limited and, as argued in Chapter 2, likely to remain limited for the foreseeable future. This suggests that, in the meantime, humans will have to do most of the work coordinating social interactions with robots.

As is evident from the fact that most proposed definitions of "social robot" focus only on criteria that a robot must fulfill to qualify as social (for a recent review of definitions, see Sarrica, Brondi, \& Fortunati, 2019), the human ability to interact socially with robots has so far largely been taken for granted. In assuming that humans are able to understand robots sufficiently well to interact with them, the proposed definitions overlook the fact that even if robots had all the social qualities that the definitions ascribe to them there might still be no social interaction between humans and robots.

This thesis engages with the question whether humans are in fact able to understand social robots sufficiently well to coordinate social interactions with them. In Section 
2.4, it was argued in that the actions of social robots may be less predictable to many of the people who will need to interact with them than the comparable actions of humans, because robots - especially those intended for social interaction - are likely to be technologically opaque: it can be difficult to understand why they take the actions they do. Importantly, this makes them difficult to predict and, as a consequence, potentially difficult to interact with.

The phenomenon of technological opacity is generally related to the underlying complexity of technological systems (Surden \& Williams, 2016). Part of the reason that robots intended for social interaction may be technologically opaque is the complicated nature of social interactions. Interacting socially is a difficult task, so a system capable of engaging autonomously in social interaction with people is necessarily going to be complex. The hardware and software components of robotic systems are likely to interact in intricate ways to produce desired social behavior. In the case of such a complicated system, it may be particularly difficult to convey - in technical terms - what the system is doing and why, in a manner that is meaningful to people.

Chapter 3 argued that people might be able to interact socially with robots despite the issue of technological opacity. When a robot's technical constitution or design eludes a person, the person might still be able to predict the behavior of the robot based on the assumption that it will act in accordance with intentional states that are ascribed to it, i.e., based on taking the intentional stance toward the robot. It was argued that, as humans, our ability to interact with robots based on treating them as intentional agents, i.e., agents with beliefs, desires, and other intentional states, depends on our ability to attribute intentional states that are behaviorally congruent. We referred to this as the intentionality attribution problem. The intentionality attribution problem (and its subproblems, such as the perceptual belief problem described in Section 4.3) is challenging because the various capabilities and limitations of robots are, in contrast to those of humans and animals, not constrained by evolutionary and cultural history. As a consequence, the problem space a person is confronted with when trying to figure out what beliefs, desires, and other intentional states to ascribe to a robot is large and difficult to navigate. For every candidate ascription, there is a potentially infinitely large number of alternative ascriptions that are equally compatible with the situation at hand. How do we decide which specific intentional states to ascribe to a robot? Section 3.2 elaborated that people (just like robots attempting to predict human behavior) must rely on folk-psychological assumptions to tacitly rule out ascriptions that are unlikely to apply to the situation at hand. In other words, the solution to the intentionality attribution problem depends on the extent to which people are able to make instantaneous, unconscious judgements about the likely actions of robots based on their folk-psychological understanding of them. It was proposed in Section 3.3 that two different "strategies" can be adopted to solve the intentionality attribution problem: one can attribute intentional states to a robot based on the 
assumption that one's pre-existing knowledge about the psychology of humans and non-human animals generalizes to the robot in question or based on the assumption that one's knowledge about the psychology of other (types of) robots generalizes to the robot in question. The general viability of these two strategies was referred to as the extendability question and the integrability question, respectively. It was proposed that the scope and limits of people's ability to interact with robots by treating them as intentional agents may ultimately depend on how these questions are resolved.

In Chapter 5, a general research methodology was proposed for studying people's ability to interact with robots by treating them as intentional agents. The methodology is based on the idea that, because (as elaborated in Chapters 1 and 2) people's interactions (with robots) are guided by their predictions of (robot) behavior, it is possible to study people's ability to interact with robots by observing how they predict their behavior - including when they manage (or do not) to get their predictions right. The methodology provides the means to experimentally observe people's predictions of robot behavior and to reliably infer the attribution of specific intentional states and the folk-psychological assumptions on which the attributions are based. Importantly, elucidating the folk-psychological assumptions that drive intentional prediction of robot behavior is incentivized by the opportunity to improve human-robot interactions by design that facilitates behavior-congruent attribution. For example, if it is discovered that people generally have difficulties understanding what a particular robot can or cannot see in (and therefore know about) a particular environment (cf. Paper V), it might be possible to solve or mitigate this problem by, for instance, redesigning the appearance of the robot so that it creates the appropriate expectations (Ziemke, 2020; Habibovic et al., 2018) or by providing verbal instructions to people about the capabilities and limitations of the robot (see also Section 5.2.2 in Paper IV for other types of possible practical solutions to the perceptual belief problem).

\subsection{Limitations}

It should be noted, as a general limitation, that so far the proposed methodology has only been applied in experiments (Paper V) that involve video representations of robots as opposed to live interactions with robots ${ }^{1}$. This is a potential threat to the ecological validity of the obtained findings. The generalizability of lab-based findings on human-robot interactions to the real world remains generally unclear (Jung \& Hinds, 2018). On the one hand, there is no obvious a priori reason why the obtained results would differ if the studies were conducted in the wild; on the other hand, the possibility that they might differ cannot be excluded on a priori grounds. Hence, the assessment of the ecological validity of the results requires that they are replicated in non-laboratory settings. This means that it would be preferable to adapt the pro-

\footnotetext{
${ }^{1}$ Similar concerns apply to the studies reported in Papers I and II, which relied on pictorial and verbal representations of robot behavior as experimental stimuli.
} 
posed methodology for use in the context of live human-robot interactions. While this is likely to be possible, considerable effort may be required to maintain the experimental control afforded by the use of pictorial or video-based stimulus materials. There are also probably other ways to approach the intentionality attribution problem that are complementary to - and possibly better than - the approach presented in this thesis. The presented methodology can be used to study the folk-psychological basis for people's predictions of robot behavior and has the advantage that it does not necessarily rely on verbal, self-reported evidence in the assessment of intentional state attribution. But clearly a fuller understanding of how people deal with attributing intentional states to robots will require a richer toolbox of alternative and complementary approaches.

Another concern regarding the external validity of the obtained study results is the degree to which they can be generalized to a larger target group than the study sample. For example, the results from the study reported in Paper V demonstrate that the participant sample were unable to reliably predict the behavior of a robot in a specific situation. While we presently see no a priori reason why the results would not generalize to other participant demographics, such as to individuals of different age, cultural backgrounds, or technical competencies, we cannot infer this conclusively without further investigation. Similarly, it is clearly possible that people might be able to better predict the behavior of a different robot, in the specific scenario, than the one used in Paper V (e.g., one with a different physical appearance). However, assessing the universality of the human ability to predict the behavior of robots based on the intentional stance is beyond the scope of any one paper or thesis. To do this, it is important that the results are replicated within a reasonable range of different types of participant demographies, robots, and settings.

The experimental work presented in this thesis provides several empirical contributions to the understanding of the scope and limits of people's ability to interact with robots by treating them as intentional agents. The results of Papers I-II - which focused on attributions of intentional states to humans versus humanoid robots and automated vehicles, respectively - suggest that people attribute the behavior of a wide range of robotic systems to underlying intentional states. This is further supported by the systematic review of the previous literature reported in Paper VI, which collated findings on mental state attribution to different types of robots (categorized as anthropomorphic, zoomorphic, and functional). However, it is important to note that neither the previous literature nor Papers I-II provide reliable evidence that people use these ascriptions to predict behavior. In other words, they did not directly assess the scope and limits of people's ability to interact with robots based on treating them as intentional agents (the central topic of the thesis). The study reported in Paper V, by contrast, which applied the methodology presented in Chapter 5, provides several important findings that validate the claim that the intentionality attribution problem 
is a significant problem in human-robot interaction. Importantly, it demonstrates a case where: (1) the behavior of a robot (due to the interpreter's lack of of understanding of the underlying technology) could only be predicted based on attributing it to a particular intentional state (a specific belief); (2) study participants were unable to consistently predict the behavior of the robot in realistic scenarios that people are able to solve consistently and effortlessly when the target agent is a human being; (3) study participants were able to improve their predictions over time as they observed the robot interact with the environment. The first point speaks to the importance of people's understanding of social robots as intentional agents to their ability to predict their behavior. The second and third points provide insights into the limits of people's understanding of robots as intentional agents. The second point reveals a significant limitation in the extendability of human/animal folk psychology to interactions with robots and the third point demonstrates some degree of integrability of experiences with robots into a workable folk psychology.

This thesis does not purport to offer a final answer to the extendability and integrability questions. It has studied some of the folk-psychological assumptions that people employ in interpretations of robots to solve the intentionality attribution problem. Clearly, people's folk-psychological assumptions about robots, such as what they are likely to want, believe, and be capable of, are likely to vary in different real-world scenarios in which they might encounter robots. It is crucial that these variations - and the human capability to deal with them - are identified and studied in much more detail than they have been so far.

\subsection{Outlook}

A central claim of this thesis is that people's understanding of social robots as intentional agents, i.e., agents with beliefs, desires, and other intentional states, is important to their ability to interact with them. For example, when people do not have a full understanding of the internal constitution or design of a robot they might in some cases have to attribute (behavior-congruent) intentional states to interact with it (such as with participants in the study of Paper V). A second central claim is that people's understanding of social robots as intentional agents may, due to significant differences between humans and robots, be limited by the (in)applicability of folk psychology in human-robot interactions. Taken together, these two claims imply that studying the attribution of intentional states to robots (and the underlying folk-psychological mechanisms) should be a central undertaking of research that aims to understand and design social interactions with robots. On this basis, it is possible to envision a future line of research within the field of human-robot interaction devoted to this endeavor ${ }^{2}$.

\footnotetext{
${ }^{2}$ The aims and methods of this line of research would to some extent resemble cognitive ethology, i.e., the study of non-human animal minds (D. Griffin, 1976; Ristau, 1991; Allen \& Bekoff, 1999). For example, the methodology proposed in Chapter 5 in this thesis bears some similarity to cognitive ethological meth-
} 
Conceived as the study of people's understanding of robots as intentional agents and how such understanding affects their ability to interact with them, the envisioned line of research would subsume some of the research that is currently being pursued under the banner explainable robotics (de Graaf, Dragan, Malle, \& Ziemke, 2021; de Graaf et al., 2018; Anjomshoae, Najjar, Calvaresi, \& Främling, 2019) and which is also associated with notions such as understandability (Hellström \& Bensch, 2018), transparency (Wachter, Mittelstadt, \& Floridi, 2017; Lyons, 2013), predictability (Zhang et al., 2017; Dragan, Lee, \& Srinivasa, 2013), interpretability (Hayes \& Shah, 2017; Mercado et al., 2016), explicability (Zhang et al., 2017), and legibility (Dragan et al., 2013). These overlapping lines of research have a common denominator: they all to some extent assume that studying the attribution of intentional states (e.g., beliefs, desires, intentions) to robots is important to making robots and robot behavior explainable/understandable/predictable/understandable/ transparent/interpretable/explicable/legible. For example, on the topic of understandability, Hellström and Bensch (2018) stated, "One important aspect of understanding concerns goal-directed actions and intentions ... desires, knowledge and beliefs, emotions, perception, capabilities, and limitations of the robot." Regarding the explainability of robot behavior, de Graaf and Malle (2017) predicted that in the future "people will regard most [autonomous intelligent systems] as intentional agents and apply the conceptual framework and psychological mechanisms of human behavior explanation to them."

The significance of studying people's understanding of robots as intentional agents depends on the extent to which people in fact rely on the intentional stance to predict behavior in interactions with robots. The scientific understanding of what makes robotic systems understandable and predictable to the people who interact with them is likely to be informed by research on other forms of understanding, such as knowledge about the technical details and design of the system. This thesis puts forward the argument that, due to the likely diversification and increased complexity of robotic technologies, social robots are destined to become increasingly technologically opaque (i.e., difficult to understand from a technical point of view). This means that, as an interpretative strategy used by people to cope with interactions with robots, the intentional stance may become increasingly relevant in the future. It should be noted, however, as explained in Section 3.1, that which kinds of robots (and other systems) can be interacted with - or maybe that can only be interacted with - based on the intentional stance is ultimately an empirical question (Bossi et al., 2020). Clearly, the full extent of people's dependency on the intentional stance to interact with robots must be assessed in reference to the full range of circumstances in which people may interact with robots.

ods discussed in Dennett (1983). However, in contrast to cognitive ethology, it would be concerned with folk taxonomies of robot minds as opposed to aspiring to a scientific taxonomy in the sense of claiming the existence of particular mental states and capacities. 
There are significant practical incentives to studying the folk-psychological mechanisms that govern people's attribution of intentional states to robots. In particular, identifying cases of misguided attributions opens up for possibilities to achieve more desirable interaction outcomes through design that facilitates prediction of robot behavior. These prospects aside, it is worth emphasizing that, because human sociocognitive capabilities evolved to cope with a social world primarily inhabited by humans and other living animals, our understanding of robots may be inherently limited by our human nature. Nature has conservatively endowed each generation of humans and other animal species with a similar set of capabilities, dependencies, and limitations. To the extent that our social interactions depend on the assumption that individuals within a species are similar to one another, it may be inherently difficult for people to interact socially with robots, whose capabilities, dependencies, and limitations are not constrained by nature but subject to fast-paced development and diversification. The consequences of this are still largely unknown. However, as robots become increasingly present in people's social lives they are clearly worthwhile exploring from both practical and scientific perspectives.

\section{Back to the Future}

In the introductory example, four-year-old Elsa and her father were unable to predict that - or understand why - Rocky, the family's lawn-mower robot, would shred toys left on the lawn. When Elsa is a grown-up, she is likely to encounter more interactive robots, such as maybe robot receptionists in hotels, robot guides at airports, or (partially) automated vehicles in public traffic. By the time her father is a senior citizen, he might encounter robot nurses in his care home. Given that such robots will need to be significantly more complex and more interactive than Rocky, they are unlikely to be less technologically opaque. Elsa and her father will therefore probably still need to rely on their interpretation of robots as intentional agents with beliefs, desires, and so on. Will this allow them to interact smoothly and purposefully with these robots? That is an empirical question to which this thesis - naturally - has no definite answer at this point. The tentative answer presented here is that it will depend on the degree to which the folk-psychological mechanisms that govern the attribution of intentional states can be put to work in the context of human-robot interaction. Hopefully, this thesis will inform and inspire fruitful future research on this important topic, and thereby contribute to making robots parts of our social world. 


\section{Bibliography}

Abubshait, A., Momen, A., \& Wiese, E. (2020). Pre-exposure to ambiguous faces modulates top-down control of attentional orienting to counterpredictive gaze cues. Frontiers in Psychology, 11, 2234. doi:10.3389/fpsyg.2020.02234

Abubshait, A. \& Wiese, E. (2017). You look human, but act like a machine: agent appearance and behavior modulate different aspects of human-robot interaction. Frontiers in Psychology, 8, 1393. doi:10.3389/fpsyg.2017.01393

Admoni, H. \& Scassellati, B. (2017). Social eye gaze in human-robot interaction: a review. Journal of Human-Robot Interaction, 6(1), 25-63.

Allen, C. \& Bekoff, M. (1999). Species of mind: the philosophy and biology of cognitive ethology.

Anjomshoae, S., Najjar, A., Calvaresi, D., \& Främling, K. (2019). Explainable agents and robots: results from a systematic literature review. In 18th International conference on autonomous agents and multiagent systems (AAMAS) (pp. 10781088). International Foundation for Autonomous Agents and Multiagent Systems.

Baker, L. (1999). Folk psychology. In R. Wilson \& F. Keil (Eds.), MIT encyclopedia of cognitive science (pp. 317-318). MIT Press.

Banks, J. (2020). Theory of mind in social robots: replication of five established human tests. International Journal of Social Robotics, 12, 403-414.

Baron-Cohen, S., Leslie, A., \& Frith, U. (1985). Does the autistic child have a "theory of mind"? Cognition, 21(1), 37-46. 
Belpaeme, T., Kennedy, J., Ramachandran, A., Scassellati, B., \& Tanaka, F. (2018). Social robots for education: a review. Science Robotics, 3(21). doi:10.1126/ scirobotics.aat5954

Benitti, F. (2012). Exploring the educational potential of robotics in schools: a systematic review. Computers \& Education, 58(3), 978-988.

Borg, E. (2018). On deflationary accounts of human action understanding. Review of Philosophy and Psychology, 9(3), 503-522.

Bossi, F., Willemse, C., Cavazza, J., Marchesi, S., Murino, V., \& Wykowska, A. (2020). The human brain reveals resting state activity patterns that are predictive of biases in attitudes towards robots. Science Robotics, 5(46). doi:10.1126/ scirobotics.aat 5954

Brentano, F. (2012). Psychology from an empirical standpoint. Routledge.

Brinck, I. \& Balkenius, C. (2020). Mutual recognition in human-robot interaction: a deflationary account. Philosophy \& Technology, 33(1), 53-70.

Broekens, J., Heerink, M., \& Rosendal, H. (2009). Assistive social robots in elderly care: a review. Gerontechnology, 8(2), 94-103.

Brooks, R. (1991). Intelligence without representation. Artificial Intelligence, 47(1-3), 139-159.

Brooks, R. (2017). The seven deadly sins of ai predictions. MIT Technology Review, 120, 79-86.

Buzan, B. (1993). From international system to international society: structural realism and regime theory meet the english school. International Organization, 47(3), 327-352.

Cabibihan, J.-J., Javed, H., Ang, M., \& Aljunied, S. M. (2013). Why robots? a survey on the roles and benefits of social robots in the therapy of children with autism. International Journal of Social Robotics, 5(4), 593-618.

Čaić, M., Odekerken-Schröder, G., \& Mahr, D. (2018). Service robots: value cocreation and co-destruction in elderly care networks. Journal of Service Management, 29(2), 178-206.

Churchland, P. (1981). Eliminative materialism and propositional attitudes. The Journal of Philosophy, 78(2), 67-90.

Clark, A. (1998). Being there: putting brain, body, and world together again. MIT Press.

Clark, H. \& Marshall, C. (1981). Definite knowledge and mutual knowledge. In A. Joshi, B. Webber, \& I. Sag (Eds.), Elements of discourse understanding (pp. 1063). Cambridge University Press.

Clements, W. \& Perner, J. (1994). Implicit understanding of belief. Cognitive Development, 9(4), 377-395.

Csibra, G. \& Gergely, G. (2007). 'obsessed with goals': functions and mechanisms of teleological interpretation of actions in humans. Acta Psychologica, 124(1), 6078.

Daly, C. (2013). Psychology and indispensability. The Monist, 96(4), 561-581. 
Dautenhahn, K. (2007). Socially intelligent robots: dimensions of human-robot interaction. Philosophical Transactions of the Royal Society B: Biological Sciences, 362(1480), 679-704.

Davis, E. \& Marcus, G. (2015). Commonsense reasoning and commonsense knowledge in artificial intelligence. Communications of the ACM, 58(9), 92-103.

de Graaf, M. \& Allouch, S. (2013). Exploring influencing variables for the acceptance of social robots. Robotics and Autonomous Systems, 61(12), 1476-1486.

de Graaf, M., Ben Allouch, S., \& van Dijk, J. (2019). Why would I use this in my home? a model of domestic social robot acceptance. Human-Computer Interaction, 34(2), 115-173.

de Graaf, M., Dragan, A., Malle, B., \& Ziemke, T. (2021). Introduction to the special issue on explainable robotic systems. ACM Transactions on Human-Robot Interaction, 10(3). doi:10.1145/3461597

de Graaf, M. \& Malle, B. (2017). How people explain action (and autonomous intelligent systems should too). In Proceedings of the 2017 AAAI fall symposium series (pp. 19-26). AAAI.

de Graaf, M. \& Malle, B. (2019). People’s explanations of robot behavior subtly reveal mental state inferences. In Proceedings of the 2019 ACM/IEEE international conference on human-robot interaction (pp. 239-248). IEEE.

de Graaf, M., Malle, B., Dragan, A., \& Ziemke, T. (2018). Explainable robotic systems. In Companion of the 2018 ACM/IEEE international conference on human-robot interaction (pp. 387-388). IEEE.

Dennett, D. (1971). Intentional systems. The Journal of Philosophy, 68(4), 87-106.

Dennett, D. (1983). Intentional systems in cognitive ethology: the "panglossian paradigm" defended. Behavioral and Brain Sciences, 6(3), 343-90.

Dennett, D. (1989). The intentional stance. MIT Press.

Dennett, D. (1991). Two contrasts: folk craft versus folk science and belief versus opinion. In J. Greenwood (Ed.), The future of folk psychology: intentionality and cognitive (pp. 135-148). Cambridge University Press.

Dennett, D. (2017). Brainstorms: philosophical essays on mind and psychology. MIT Press.

Donaldson, S. \& Grant-Vallone, E. (2002). Understanding self-report bias in organizational behavior research. Journal of Business and Psychology, 17(2), 245-260.

Dragan, A., Lee, K., \& Srinivasa, S. (2013). Legibility and predictability of robot motion. In Proceedings of the 8th ACM/IEEE international conference on humanrobot interaction (pp. 301-308). IEEE.

Dretske, F. (1991). Explaining behavior: reasons in a world of causes. MIT Press.

Dreyfus, H. (1992). What computers still can't do: a critique of artificial reason. MIT Press.

Dreyfus, H. (2012). A history of first step fallacies. Minds and Machines, 22(2), 87-99. 
Eriksson, J., Mataric, M., \& Winstein, C. (2005). Hands-off assistive robotics for post-stroke arm rehabilitation. In 9th International conference on rehabilitation robotics (pp. 21-24). IEEE.

Feil-Seifer, D. \& Mataric, M. (2005). Defining socially assistive robotics. In Proceedings of the 9 th international conference on rehabilitation robotics (pp. 465-468). IEEE.

FeldmanHall, O. \& Shenhav, A. (2019). Resolving uncertainty in a social world. Nature Human Behaviour, 3(5), 426-435.

Fodor, J. (1975). The language of thought. Harvard University Press.

Fodor, J. (1983). The modularity of mind. MIT Press.

Fodor, J. (1987). Psychosemantics: the problem of meaning in the philosophy of mind. MIT Press.

Fong, T., Nourbakhsh, I., \& Dautenhahn, K. (2003). A survey of socially interactive robots. Robotics and Autonomous Systems, 42(3-4), 143-166.

Gaudiello, I., Zibetti, E., Lefort, S., Chetouani, M., \& Ivaldi, S. (2016). Trust as indicator of robot functional and social acceptance. an experimental study on user conformation to icub answers. Computers in Human Behavior, 61, 633-655.

Goldman, A. (1989). Interpretation psychologized. Mind \& Language, 4(3), 161-185.

Goldman, A. (2000). The mentalizing folk. In D. Sperber (Ed.), Metarepresentations: a multidisciplinary perspective (pp. 7-34). Oxford University Press.

Gordon, R. (1986). Folk psychology as simulation. Mind \& language, 1(2), 158-171.

Gordon, R. (1992). The simulation theory: objections and misconceptions. Mind \& Language, 7(1-2), 11-34.

Gray, H., Gray, K., \& Wegner, D. (2007). Dimensions of mind perception. Science, 315(5812), 619.

Greenwald, A. \& Banaji, M. (1995). Implicit social cognition: attitudes, self-esteem, and stereotypes. Psychological Review, 102(1), 4-27.

Griffin, D. (1976). The question of animal awareness: evolutionary continuity of mental experience. Rockefeller University Press.

Griffin, R. \& Baron-Cohen, S. (2002). The intentional stance: developmental and neurocognitive perspectives. In A. Brook \& D. Ross (Eds.), Daniel Dennett (pp. 83116). Cambridge University Press.

Habibovic, A., Lundgren, V. M., Andersson, J., Klingegård, M., Lagström, T., Sirkka, A., ..., Krupenia, S., et al. (2018). Communicating intent of automated vehicles to pedestrians. Frontiers in Psychology, 9, 1336.

Hancock, P., Billings, D., Schaefer, K., Chen, J., De Visser, E., \& Parasuraman, R. (2011). A meta-analysis of factors affecting trust in human-robot interaction. Human Factors, 53(5), 517-527.

Hayes, B. \& Shah, J. (2017). Improving robot controller transparency through autonomous policy explanation. In Proceedings of the 2017 ACM/IEEE international conference on human-robot interaction (pp. 303-312). IEEE.

Heider, F. (1958). The psychology of interpersonal relations. New York: Wiley. 
Hellström, T. \& Bensch, S. (2018). Understandable robots-what, why, and how. Paladyn, 9(1), 110-123.

Hutto, D. (2012). Folk psychological narratives: the sociocultural basis of understanding reasons. MIT Press.

Jordan, M. \& Mitchell, T. (2015). Machine learning: trends, perspectives, and prospects. Science, 349(6245), 255-260.

Jung, M. \& Hinds, P. (2018). Robots in the wild: a time for more robust theories of human-robot interaction. ACM Transactions on Human-Robot Interaction, 7(1). doi:10.1145/3208975

Keijsers, M. \& Bartneck, C. (2018). Mindless robots get bullied. In Proceedings of the 2018 ACM/IEEE international conference on human-robot interaction (pp. 205214).

Kitchenham, B. \& Charters, S. (2007). Guidelines for performing systematic literature reviews in software engineering. Version 2.3, EBSE Technical Report, EBSE200701, Keele University.

Kobayashi, H. \& Kohshima, S. (1997). Unique morphology of the human eye. Nature, 387(6635), 767-768.

Kovács, Á., Téglás, E., \& Endress, D. (2010). The social sense: susceptibility to others' beliefs in human infants and adults. Science, 330(6012), 1830-1834.

Lake, B., Ullman, T., Tenenbaum, J., \& Gershman, S. (2017). Building machines that learn and think like people. Behavioral and Brain Sciences, 40, e253.

Lee, S.-L., Lau, I., Kiesler, S., \& Chiu, C.-Y. (2005). Human mental models of humanoid robots. In Proceedings of the 2005 IEEE international conference on robotics and automation (pp. 2767-2772).

Levesque, H. (2017). Common sense, the Turing test, and the quest for real AI. MIT Press.

Levin, D., Killingsworth, S., Saylor, M., Gordon, S., \& Kawamura, K. (2013). Tests of concepts about different kinds of minds: predictions about the behavior of computers, robots, and people. Human-Computer Interaction, 28(2), 161-191.

List, C. \& Pettit, P. (2011). Group agency: the possibility, design, and status of corporate agents. Oxford University Press.

Litman, T. (2021). Autonomous vehicle implementation predictions: implications for transport planning. Victoria Transport Policy Institute: Victoria, Canada.

Lyons, J. (2013). Being transparent about transparency: a model for human-robot interaction. In Proceedings of the 2013 AAAI spring symposium series. AAAI.

Malle, B. (2006). How the mind explains behavior: folk explanations, meaning, and social interaction. MIT Press.

Malle, B. \& Knobe, J. (1997). The folk concept of intentionality. Journal of Experimental Social Psychology, 33(2), 101-121.

Manzi, F., Peretti, G., Di Dio, C., Cangelosi, A., Itakura, S., Kanda, T., ... Marchetti, A. (2020). A robot is not worth another: exploring children's mental state attribution to different humanoid robots. Frontiers in Psychology, 11, 2011. 
Martini, M., Gonzalez, C., \& Wiese, E. (2016). Seeing minds in others-can agents with robotic appearance have human-like preferences? PLOS ONE, 11(1), e0146310.

McCarthy, J. (1960). Programs with common sense. RLE and MIT computation center. Meltzoff, A., Brooks, R., Shon, A., \& Rao, R. (2010). "Social” robots are psychological agents for infants: a test of gaze following. Neural Networks, 23(8-9), 966-972.

Mercado, J., Rupp, M., Chen, J., Barnes, M., Barber, D., \& Procci, K. (2016). Intelligent agent transparency in human-agent teaming for multi-UxV management. Human Factors, 58(3), 401-415.

Miller, T. (2019). Explanation in artificial intelligence: insights from the social sciences. Artificial Intelligence, 267, 1-38.

Mitchell, M. (2021). Why AI is harder than we think. arXiv: 2104.12871 [cs.AI]

Moorman, R. \& Podsakoff, P. (1992). A meta-analytic review and empirical test of the potential confounding effects of social desirability response sets in organizational behaviour research. Journal of Occupational and Organizational Psychology, 65(2), 131-149.

Morton, A. (1980). Frames of mind: constraints on the common-sense conception of the mental. Clarendon.

Mou, W., Ruocco, M., Zanatto, D., \& Cangelosi, A. (2020). When would you trust a robot? a study on trust and theory of mind in human-robot interactions. In Proceedings of the 29th IEEE international conference on robot and human interactive communication (pp. 956-962). IEEE.

Nichols, S. (2006). Folk psychology. In Encyclopedia of cognitive science. London: Nature Publishing Group.

Nickerson, R. (1999). How we know - and sometimes misjudge - what others know: imputing one's own knowledge to others. Psychological Bulletin, 125(6), 737759.

Nisbett, R. \& Wilson, T. (1977). Telling more than we can know: verbal reports on mental processes. Psychological Review, 84(3), 231.

Okanda, M., Taniguchi, K., Wang, Y., \& Itakura, S. (2021). Preschoolers' and adults' animism tendencies toward a humanoid robot. Computers in Human Behavior, $118,106688$.

Papagni, G. \& Koeszegi, S. (2021). A pragmatic approach to the intentional stance semantic, empirical and ethical considerations for the design of artificial agents. Minds and Machines, 1-30.

Paulhus, D. \& Vazire, S. (2007). The self-report method. In R. W. Robins, R. C. Fraley, \& R. F. Krueger (Eds.), Handbook of research methods in personality psychology (pp. 224-239). Guilford Press.

Perez-Osorio, J., Marchesi, S., Ghiglino, D., Ince, M., \& Wykowska, A. (2019). More than you expect: priors influence on the adoption of intentional stance toward humanoid robots. In M. A. Salichs, S. S. Ge, E. I. Barakova, J.-J. Cabibihan, A. R. Wagner, Á. Castro-González, \& H. He (Eds.), Social robotics (pp. 119129). Cham: Springer International Publishing. 
Perez-Osorio, J. \& Wykowska, A. (2020). Adopting the intentional stance toward natural and artificial agents. Philosophical Psychology, 33(3), 369-395.

Petrovych, V., Thellman, S., \& Ziemke, T. (2018). Human interpretation of goaldirected autonomous car behavior. In The 40th annual cognitive science society meeting, Madison, Wisconsin, USA, July 25-28 (pp. 2235-2240). Cognitive Science Society.

Podsakoff, P. \& Organ, D. (1986). Self-reports in organizational research: problems and prospects. Journal of management, 12(4), 531-544.

Powers, A., Kramer, A., Lim, S., Kuo, J., Lee, S.-l., \& Kiesler, S. (2005). Eliciting information from people with a gendered humanoid robot. In Proceedings of the 2005 IEEE international workshop on robot and human interactive communication (pp. 158-163). IEEE.

Premack, D. \& Woodruff, G. (1978). Does the chimpanzee have a theory of mind? Behavioral and Brain Sciences, 1(4), 515-526.

Pylyshyn, Z. (1980). Computation and cognition: issues in the foundations of cognitive science. Behavioral and Brain Sciences, 3(1), 111-169.

Pylyshyn, Z. (1986). Computation and cognition: toward a foundation for cognitive science. MIT Press.

Quine, W. (1961). Reference and generality. In From a logical point of view: nine logicophilosophical essays (pp. 139-159). Harvard University Press.

Reeves, B. \& Nass, C. (1996). The media equation: how people treat computers, television, and new media like real people. Cambridge University Press.

Ristau, C. (1991). Cognitive ethology: the minds of other animals: essays in honor of Donald R. Griffin. Psychology Press.

Sarrica, M., Brondi, S., \& Fortunati, L. (2019). How many facets does a "social robot" have? a review of scientific and popular definitions online. Information Technology \& People, 33(1), 1-21.

Scassellati, B., Admoni, H., \& Matarić, M. (2012). Robots for use in autism research. Annual Review of Biomedical Engineering, 14, 275-294.

Schellen, E. \& Wykowska, A. (2019). Intentional mindset toward robots-open questions and methodological challenges. Frontiers in Robotics and AI, 5, 139.

Schneider, D., Slaughter, V., \& Dux, P. (2015). What do we know about implicit falsebelief tracking? Psychonomic Bulletin \& Review, 22(1), 1-12.

Searle, J. (1983). Intentionality: an essay in the philosophy of mind. Cambridge University Press.

Searle, J. (2008). Mind, language and society: philosophy in the real world. Basic Books.

Sellars, W. (1956). Empiricism and the philosophy of mind. Minnesota Studies in the Philosophy of Science, 1(19), 253-329.

Shanahan, M., Crosby, M., Beyret, B., \& Cheke, L. (2020). Artificial intelligence and the common sense of animals. Trends in Cognitive Sciences, 24(11), 862-872.

Shanker, S. \& King, B. (2002). The emergence of a new paradigm in ape language research: beyond interactionism. Behavioral and Brain Sciences, 25(5), 646-651. 
Sherry, L., Feary, M., Polson, P., \& Palmer, E. (2001). What's it doing now? taking the covers off autopilot behavior. In Proceedings of the 11 th international symposium on aviation psychology (pp. 1-6). Ohio State University, Columbus, OH.

Simon, H. (1955). A behavioral model of rational choice. The Quarterly Journal of Economics, 69(1), 99-118.

Simon, H. (1956). Rational choice and the structure of the environment. Psychological Review, 63(2), 129.

Smith, B. (2019). The promise of artificial intelligence: reckoning and judgment. MIT Press.

Spatola, N. \& Wudarczyk, O. (2020). Implicit attitudes towards robots predict explicit attitudes, semantic distance between robots and humans, anthropomorphism, and prosocial behavior: from attitudes to human-robot interaction. International Journal of Social Robotics, 13, 1-11.

Stich, S. (1983). From folk psychology to cognitive science: the case against belief. MIT Press.

Stich, S. \& Nichols, S. (1992). Folk psychology: simulation or tacit theory? Mind \& Language, 7(1-2), 35-71.

Surden, H. \& Williams, M.-A. (2016). Technological opacity, predictability, and selfdriving cars. Cardozo Law Review, 38, 121.

Tamir, D. \& Mitchell, J. (2013). Anchoring and adjustment during social inferences. Journal of Experimental Psychology: General, 142(1), 151.

Terada, K. \& Yamada, S. (2017). Mind-reading and behavior-reading against agents with and without anthropomorphic features in a competitive situation. Frontiers in Psychology, 8, 1071. doi:10.3389/fpsyg.2017.01071

Thellman, S., de Graaf, M., \& Ziemke, T. (in review). Mental state attribution to robots: a systematic review of conceptions, methods, and findings. Submitted to ACM Transactions on Human-Robot Interaction, June 2021.

Thellman, S., Giagtzidou, A., Silvervarg, A., \& Ziemke, T. (2020). An implicit, nonverbal measure of belief attribution to robots. In Companion of the 2020 ACM/IEEE international conference on human-robot interaction (pp. 473-475). ACM.

Thellman, S., Silvervarg, A., \& Ziemke, T. (2017). Folk-psychological interpretation of human vs. humanoid robot behavior: exploring the intentional stance toward robots. Frontiers in Psychology, 8, 1962.

Thellman, S., Silvervarg, A., \& Ziemke, T. (2020). Some adults fail the false-belief task when the believer is a robot. In Companion of the 2020 ACM/IEEE international conference on human-robot interaction (pp. 479-481). ACM.

Thellman, S. \& Ziemke, T. (2019). The intentional stance toward robots: conceptual and methodological considerations. In The 41st annual conference of the cognitive science society (pp. 1097-1103). Cognitive Science Society.

Thellman, S. \& Ziemke, T. (2020). Do you see what I see? Tracking the perceptual beliefs of robots. iScience, 23(10), 101625. 
Thellman, S. \& Ziemke, T. (2021). The perceptual belief problem: Why explainability is a tough challenge in social robotics. ACM Transactions on Human-Robot Interaction, 10(3). doi:10.1145/3461781

Tversky, A. \& Kahneman, D. (1974). Judgment under uncertainty: heuristics and biases. Science, 185(4157), 1124-1131.

von Uexküll, J. (1982). The theory of meaning. Semiotica, 42(1), 25-79.

Wachter, S., Mittelstadt, B., \& Floridi, L. (2017). Transparent, explainable, and accountable AI for robotics. Science Robotics, 2(6), eaan6080.

Wallkötter, S., Stower, R., Kappas, A., \& Castellano, G. (2020). A robot by any other frame: framing and behaviour influence mind perception in virtual but not realworld environments. In Proceedings of the 2020 ACM/IEEE international conference on human-robot interaction (pp. 609-618). ACM.

Waytz, A., Morewedge, C., Epley, N., Monteleone, G., Gao, J.-H., \& Cacioppo, J. (2010). Making sense by making sentient: effectance motivation increases anthropomorphism. Journal of Personality and Social Psychology, 99(3), 410-435.

Wellman, H., Cross, D., \& Watson, J. (2001). Meta-analysis of theory-of-mind development: the truth about false belief. Child Development, 72(3), 655-684.

Wendt, A. (1999). Social theory of international politics. Cambridge University Press.

WHO. (2015). World report on ageing and health. World Health Organization.

Wiese, E., Mandell, A., Shaw, T., \& Smith, M. (2019). Implicit mind perception alters vigilance performance because of cognitive conflict processing. Journal of Experimental Psychology: Applied, 25(1), 25.

Wiese, E., Metta, G., \& Wykowska, A. (2017). Robots as intentional agents: using neuroscientific methods to make robots appear more social. Frontiers in Psychology, 8, 1663.

Wiese, E., Wykowska, A., Zwickel, J., \& Müller, H. J. (2012). I see what you mean: how attentional selection is shaped by ascribing intentions to others. PLOS ONE, 7(9), 1-7.

Wimmer, H. \& Perner, J. (1983). Beliefs about beliefs: representation and constraining function of wrong beliefs in young children's understanding of deception. Cognition, 13(1), 103-128.

Wykowska, A., Wiese, E., Prosser, A., \& Müller, H. J. (2014). Beliefs about the minds of others influence how we process sensory information. PLOS ONE, 9(4), 111.

Yang, G.-Z., Bellingham, J., Dupont, P., Fischer, P., Floridi, L., Full, R., ... Wood, R. (2018). The grand challenges of science robotics. Science Robotics, 3(14), eaar7650.

Young, J., Hawkins, R., Sharlin, E., \& Igarashi, T. (2009). Toward acceptable domestic robots: applying insights from social psychology. International Journal of Social Robotics, 1(1), 95-108.

Zhang, Y., Sreedharan, S., Kulkarni, A., Chakraborti, T., Zhuo, H. H., \& Kambhampati, S. (2017). Plan explicability and predictability for robot task planning. In 
Proceedings of the IEEE international conference on robotics and automation (pp. 1313-1320). IEEE.

Ziemke, T. (2020). Understanding robots. Science Robotics, 5, eabe2987.

Ziemke, T. \& Sharkey, N. (2001). A stroll through the worlds of robots and animals: applying jakob von uexkull's theory of meaning to adaptive robots and artificial life. Semiotica, 134(1/4), 701-746.

Złotowski, J., Sumioka, H., Eyssel, F., Nishio, S., Bartneck, C., \& Ishiguro, H. (2018). Model of dual anthropomorphism: the relationship between the media equation effect and implicit anthropomorphism. International Journal of Social Robotics, 10(5), 701-714. 


\section{Part II}

\section{Publications}





\section{Papers}

The papers associated with this thesis have been removed for copyright reasons. For more details about these see:

http://urn.kb.se/resolve?urn=urn:nbn:se:liu:diva-178806 

Department of Computer and Information Science

Linköpings universitet

\title{
Dissertations
}

\author{
Linköping Studies in Science and Technology \\ Linköping Studies in Arts and Sciences \\ Linköping Studies in Statistics \\ Linköping Studies in Information Science
}

Linköping Studies in Science and Technology

No 14 Anders Haraldsson: A Program Manipulation System Based on Partial Evaluation, 1977, ISBN 917372-144-1.

No 17 Bengt Magnhagen: Probability Based Verification of Time Margins in Digital Designs, 1977, ISBN 91-7372157-3.

No 18 Mats Cedwall: Semantisk analys av processbeskrivningar i naturligt språk, 1977, ISBN 91- 7372 168-9.

No 22 Jaak Urmi: A Machine Independent LISP Compiler and its Implications for Ideal Hardware, 1978, ISBN 91-7372-188-3.

No 33 Tore Risch: Compilation of Multiple File Queries in a Meta-Database System, 1978, ISBN 91- 7372-232-4.

No 51 Erland Jungert: Synthesizing Database Structures from a User Oriented Data Model, 1980, ISBN 917372-387-8.

No 54 Sture Hägglund: Contributions to the Development of Methods and Tools for Interactive Design of Applications Software, 1980, ISBN 91-7372-404-1.

No 55 Pär Emanuelson: Performance Enhancement in a Well-Structured Pattern Matcher through Partial Evaluation, 1980, ISBN 91-7372-403-3.

No 58 Bengt Johnsson, Bertil Andersson: The HumanComputer Interface in Commercial Systems, 1981, ISBN 91-7372-414-9.

No 69 H. Jan Komorowski: A Specification of an Abstract Prolog Machine and its Application to Partial Evaluation, 1981, ISBN 91-7372-479-3.

No 71 René Reboh: Knowledge Engineering Techniques and Tools for Expert Systems, 1981, ISBN 91-7372489-0.

No 77 Östen Oskarsson: Mechanisms of Modifiability in large Software Systems, 1982, ISBN 91- 7372-527-7.

No 94 Hans Lunell: Code Generator Writing Systems, 1983, ISBN 91-7372-652-4.

No 97 Andrzej Lingas: Advances in Minimum Weight Triangulation, 1983, ISBN 91-7372-660-5

No 109 Peter Fritzson: Towards a Distributed Programming Environment based on Incremental Compilation, 1984, ISBN 91-7372-801-2.

No 111 Erik Tengvald: The Design of Expert Planning Systems. An Experimental Operations Planning System for Turning, 1984, ISBN 91-7372- 805-5.

No 155 Christos Levcopoulos: Heuristics for Minimum Decompositions of Polygons, 1987, ISBN 91-7870133-3.

No 165 James W. Goodwin: A Theory and System for NonMonotonic Reasoning, 1987, ISBN 91-7870-183-X.

No 170 Zebo Peng: A Formal Methodology for Automated Synthesis of VLSI Systems, 1987, ISBN 91-7870-225-9.

No 174 Johan Fagerström: A Paradigm and System for Design of Distributed Systems, 1988, ISBN 91-7870301-8.
No 192 Dimiter Driankov: Towards a Many Valued Logic of Quantified Belief, 1988, ISBN 91-7870-374-3.

No 213 Lin Padgham: Non-Monotonic Inheritance for an Object Oriented Knowledge Base, 1989, ISBN 917870-485-5.

No 214 Tony Larsson: A Formal Hardware Description and Verification Method, 1989, ISBN 91-7870-517-7.

No 221 Michael Reinfrank: Fundamentals and Logical Foundations of Truth Maintenance, 1989, ISBN 917870-546-0.

No 239 Jonas Löwgren: Knowledge-Based Design Support and Discourse Management in User Interface Management Systems, 1991, ISBN 91-7870-720-X.

No 244 Henrik Eriksson: Meta-Tool Support for Knowledge Acquisition, 1991, ISBN 91-7870-746-3.

No 252 Peter Eklund: An Epistemic Approach to Interactive Design in Multiple Inheritance Hierarchies, 1991, ISBN 91-7870-784-6.

No 258 Patrick Doherty: NML3 - A Non-Monotonic Formalism with Explicit Defaults, 1991, ISBN 917870-816-8.

No 260 Nahid Shahmehri: Generalized Algorithmic Debugging, 1991, ISBN 91-7870-828-1.

No 264 Nils Dahlbäck: Representation of DiscourseCognitive and Computational Aspects, 1992, ISBN 91-7870-850-8.

No 265 Ulf Nilsson: Abstract Interpretations and Abstract Machines: Contributions to a Methodology for the Implementation of Logic Programs, 1992, ISBN 917870-858-3.

No 270 Ralph Rönnquist: Theory and Practice of Tensebound Object References, 1992, ISBN 91-7870-873-7.

No 273 Björn Fjellborg: Pipeline Extraction for VLSI Data Path Synthesis, 1992, ISBN 91-7870-880-X.

No 276 Staffan Bonnier: A Formal Basis for Horn Clause Logic with External Polymorphic Functions, 1992, ISBN 91-7870-896-6.

No 277 Kristian Sandahl: Developing Knowledge Management Systems with an Active Expert Methodology, 1992, ISBN 91-7870-897-4.

No 281 Christer Bäckström: Computational Complexity of Reasoning about Plans, 1992, ISBN 91-7870-979-2.

No 292 Mats Wirén: Studies in Incremental Natural Language Analysis, 1992, ISBN 91-7871-027-8.

No 297 Mariam Kamkar: Interprocedural Dynamic Slicing with Applications to Debugging and Testing, 1993, ISBN 91-7871-065-0.

No 302 Tingting Zhang: A Study in Diagnosis Using Classification and Defaults, 1993, ISBN 91-7871-0782.

No 312 Arne Jönsson: Dialogue Management for Natural Language Interfaces - An Empirical Approach, 1993, ISBN 91-7871-110-X

No 338 Simin Nadjm-Tehrani: Reactive Systems in Physical Environments: Compositional Modelling and Framework for Verification, 1994, ISBN 91-7871-237-8. 
No 371 Bengt Savén: Business Models for Decision Support and Learning. A Study of Discrete-Event Manufacturing Simulation at Asea/ABB 1968-1993, 1995, ISBN 91-7871-494-X.

No 375 Ulf Söderman: Conceptual Modelling of Mode Switching Physical Systems, 1995, ISBN 91-7871-5164.

No 383 Andreas Kågedal: Exploiting Groundness in Logic Programs, 1995, ISBN 91-7871-538-5.

No 396 George Fodor: Ontological Control, Description, Identification and Recovery from Problematic Control Situations, 1995, ISBN 91-7871-603-9.

No 413 Mikael Pettersson: Compiling Natural Semantics, 1995, ISBN 91-7871-641-1.

No 414 Xinli Gu: RT Level Testability Improvement by Testability Analysis and Transformations, 1996, ISBN 91-7871-654-3.

No 416 Hua Shu: Distributed Default Reasoning, 1996, ISBN 91-7871-665-9.

No 429 Jaime Villegas: Simulation Supported Industrial Training from an Organisational Learning Perspective - Development and Evaluation of the SSIT Method, 1996, ISBN 91-7871-700-0.

No 431 Peter Jonsson: Studies in Action Planning: Algorithms and Complexity, 1996, ISBN 91-7871-7043.

No 437 Johan Boye: Directional Types in Logic Programming, 1996, ISBN 91-7871-725-6.

No 439 Cecilia Sjöberg: Activities, Voices and Arenas: Participatory Design in Practice, 1996, ISBN 91-7871728-0.

No 448 Patrick Lambrix: Part-Whole Reasoning in Description Logics, 1996, ISBN 91-7871-820-1.

No 452 Kjell Orsborn: On Extensible and Object-Relational Database Technology for Finite Element Analysis Applications, 1996, ISBN 91-7871-827-9.

No 459 Olof Johansson: Development Environments for Complex Product Models, 1996, ISBN 91-7871-855-4.

No 461 Lena Strömbäck: User-Defined Constructions in Unification-Based Formalisms, 1997, ISBN 91-7871857-0.

No 462 Lars Degerstedt: Tabulation-based Logic Programming: A Multi-Level View of Query Answering, 1996, ISBN 91-7871-858-9.

No 475 Fredrik Nilsson: Strategi och ekonomisk styrning En studie av hur ekonomiska styrsystem utformas och används efter företagsförvärv, 1997, ISBN 917871-914-3.

No 480 Mikael Lindvall: An Empirical Study of Requirements-Driven Impact Analysis in Object-Oriented Software Evolution, 1997, ISBN 91-7871-927-5.

No 485 Göran Forslund: Opinion-Based Systems: The Cooperative Perspective on Knowledge-Based Decision Support, 1997, ISBN 91-7871-938-0.

No 494 Martin Sköld: Active Database Management Systems for Monitoring and Control, 1997, ISBN 91 7219-002-7.

No 495 Hans Olsén: Automatic Verification of Petri Nets in a CLP framework, 1997, ISBN 91-7219-011-6.

No 498 Thomas Drakengren: Algorithms and Complexity for Temporal and Spatial Formalisms, 1997, ISBN 91 7219-019-1.

No 502 Jakob Axelsson: Analysis and Synthesis of Heterogeneous Real-Time Systems, 1997, ISBN 91-7219-035-3.
No 503 Johan Ringström: Compiler Generation for DataParallel Programming Languages from Two-Level Semantics Specifications, 1997, ISBN 91-7219-045-0.

No 512 Anna Moberg: Närhet och distans - Studier av kommunikationsmönster i satellitkontor och flexibla kontor, 1997, ISBN 91-7219-119-8.

No 520 Mikael Ronström: Design and Modelling of a Parallel Data Server for Telecom Applications, 1998, ISBN 91-7219-169-4

No 522 Niclas Ohlsson: Towards Effective Fault Prevention - An Empirical Study in Software Engineering, 1998, ISBN 91-7219-176-7.

No 526 Joachim Karlsson: A Systematic Approach for Prioritizing Software Requirements, 1998, ISBN 917219-184-8.

No 530 Henrik Nilsson: Declarative Debugging for Lazy Functional Languages, 1998, ISBN 91-7219-197-X.

No 555 Jonas Hallberg: Timing Issues in High-Level Synthesis, 1998, ISBN 91-7219-369-7.

No 561 Ling Lin: Management of 1-D Sequence Data - From Discrete to Continuous, 1999, ISBN 91-7219-402-2.

No 563 Eva L Ragnemalm: Student Modelling based on Collaborative Dialogue with a Learning Companion, 1999, ISBN 91-7219-412-X.

No 567 Jörgen Lindström: Does Distance matter? On geographical dispersion in organisations, 1999, ISBN 917219-439-1.

No 582 Vanja Josifovski: Design, Implementation and Evaluation of a Distributed Mediator System for Data Integration, 1999, ISBN 91-7219-482-0.

No 589 Rita Kovordányi: Modeling and Simulating Inhibitory Mechanisms in Mental Image Reinterpretation - Towards Cooperative HumanComputer Creativity, 1999, ISBN 91-7219-506-1.

No 592 Mikael Ericsson: Supporting the Use of Design Knowledge - An Assessment of Commenting Agents, 1999, ISBN 91-7219-532-0.

No 593 Lars Karlsson: Actions, Interactions and Narratives, 1999, ISBN 91-7219-534-7.

No 594 C. G. Mikael Johansson: Social and Organizational Aspects of Requirements Engineering Methods - A practice-oriented approach, 1999, ISBN 91-7219-541$\mathrm{X}$

No 595 Jörgen Hansson: Value-Driven Multi-Class Overload Management in Real-Time Database Systems, 1999, ISBN 91-7219-542-8.

No 596 Niklas Hallberg: Incorporating User Values in the Design of Information Systems and Services in the Public Sector: A Methods Approach, 1999, ISBN 917219-543-6.

No 597 Vivian Vimarlund: An Economic Perspective on the Analysis of Impacts of Information Technology: From Case Studies in Health-Care towards General Models and Theories, 1999, ISBN 91-7219-544-4.

No 598 Johan Jenvald: Methods and Tools in ComputerSupported Taskforce Training, 1999, ISBN 91-7219547-9.

No 607 Magnus Merkel: Understanding and enhancing translation by parallel text processing, 1999, ISBN 91 7219-614-9.

No 611 Silvia Coradeschi: Anchoring symbols to sensory data, 1999, ISBN 91-7219-623-8.

No 613 Man Lin: Analysis and Synthesis of Reactive Systems: A Generic Layered Architecture Perspective, 1999, ISBN 91-7219-630-0. 
No 618 Jimmy Tjäder: Systemimplementering i praktiken En studie av logiker i fyra projekt, 1999, ISBN 917219-657-2.

No 627 Vadim Engelson: Tools for Design, Interactive Simulation, and Visualization of Object-Oriented Models in Scientific Computing, 2000, ISBN 91-7219709-9.

No 637 Esa Falkenroth: Database Technology for Control and Simulation, 2000, ISBN 91-7219-766-8.

No 639 Per-Arne Persson: Bringing Power and Knowledge Together: Information Systems Design for Autonomy and Control in Command Work, 2000, ISBN 91-7219796-X.

No 660 Erik Larsson: An Integrated System-Level Design for Testability Methodology, 2000, ISBN 91-7219-890-7.

No 688 Marcus Bjäreland: Model-based Execution Monitoring, 2001, ISBN 91-7373-016-5.

No 689 Joakim Gustafsson: Extending Temporal Action Logic, 2001, ISBN 91-7373-017-3.

No 720 Carl-Johan Petri: Organizational Information Provision - Managing Mandatory and Discretionary Use of Information Technology, 2001, ISBN 91-7373-1269.

No 724 Paul Scerri: Designing Agents for Systems with Adjustable Autonomy, 2001, ISBN 91-7373-207-9.

No 725 Tim Heyer: Semantic Inspection of Software Artifacts: From Theory to Practice, 2001, ISBN 917373-208-7.

No 726 Pär Carlshamre: A Usability Perspective on Requirements Engineering - From Methodology to Product Development, 2001, ISBN 91-7373-212-5.

No 732 Juha Takkinen: From Information Management to Task Management in Electronic Mail, 2002, ISBN 917373-258-3.

No 745 Johan Åberg: Live Help Systems: An Approach to Intelligent Help for Web Information Systems, 2002, ISBN 91-7373-311-3.

No 746 Rego Granlund: Monitoring Distributed Teamwork Training, 2002, ISBN 91-7373-312-1.

No 757 Henrik André-Jönsson: Indexing Strategies for Time Series Data, 2002, ISBN 917373-346-6.

No 747 Anneli Hagdahl: Development of IT-supported Interorganisational Collaboration - A Case Study in the Swedish Public Sector, 2002, ISBN 91-7373-314-8.

No 749 Sofie Pilemalm: Information Technology for NonProfit Organisations - Extended Participatory Design of an Information System for Trade Union Shop Stewards, 2002, ISBN 91-7373-318-0.

No 765 Stefan Holmlid: Adapting users: Towards a theory of use quality, 2002, ISBN 91-7373-397-0.

No 771 Magnus Morin: Multimedia Representations of Distributed Tactical Operations, 2002, ISBN 91-7373-4217.

No 772 Pawel Pietrzak: A Type-Based Framework for Locating Errors in Constraint Logic Programs, 2002, ISBN 91-7373-422-5.

No 758 Erik Berglund: Library Communication Among Programmers Worldwide, 2002, ISBN 91-7373-349-0.

No 774 Choong-ho Yi: Modelling Object-Oriented Dynamic Systems Using a Logic-Based Framework, 2002, ISBN 91-7373-424-1.

No 779 Mathias Broxvall: A Study in the Computational Complexity of Temporal Reasoning, 2002, ISBN 917373-440-3.
No 793 Asmus Pandikow: A Generic Principle for Enabling Interoperability of Structured and Object-Oriented Analysis and Design Tools, 2002, ISBN 91-7373-479-9.

No 785 Lars Hult: Publika Informationstjänster. En studie av den Internetbaserade encyklopedins bruksegenskaper, 2003, ISBN 91-7373-461-6.

No 800 Lars Taxén: A Framework for the Coordination of Complex Systems' Development, 2003, ISBN 917373-604-X.

No 808 Klas Gäre: Tre perspektiv på förväntningar och förändringar i samband med införande av informationssystem, 2003, ISBN 91-7373-618-X.

No 821 Mikael Kindborg: Concurrent Comics programming of social agents by children, 2003, ISBN 91-7373-651-1.

No 823 Christina Ölvingson: On Development of Information Systems with GIS Functionality in Public Health Informatics: A Requirements Engineering Approach, 2003, ISBN 91-7373-656-2.

No 828 Tobias Ritzau: Memory Efficient Hard Real-Time Garbage Collection, 2003, ISBN 91-7373-666-X.

No 833 Paul Pop: Analysis and Synthesis of Communication-Intensive Heterogeneous Real-Time Systems, 2003, ISBN 91-7373-683-X.

No 852 Johan Moe: Observing the Dynamic Behaviour of Large Distributed Systems to Improve Development and Testing - An Empirical Study in Software Engineering, 2003, ISBN 91-7373-779-8.

No 867 Erik Herzog: An Approach to Systems Engineering Tool Data Representation and Exchange, 2004, ISBN 91-7373-929-4.

No 872 Aseel Berglund: Augmenting the Remote Control: Studies in Complex Information Navigation for Digital TV, 2004, ISBN 91-7373-940-5.

No 869 Jo Skåmedal: Telecommuting's Implications on Travel and Travel Patterns, 2004, ISBN 91-7373-935-9.

No 870 Linda Askenäs: The Roles of IT - Studies of Organising when Implementing and Using Enterprise Systems, 2004, ISBN 91-7373-936-7.

No 874 Annika Flycht-Eriksson: Design and Use of Ontologies in Information-Providing Dialogue Systems, 2004, ISBN 91-7373-947-2

No 873 Peter Bunus: Debugging Techniques for EquationBased Languages, 2004, ISBN 91-7373-941-3.

No 876 Jonas Mellin: Resource-Predictable and Efficient Monitoring of Events, 2004, ISBN 91-7373-956-1.

No 883 Magnus Bång: Computing at the Speed of Paper: Ubiquitous Computing Environments for Healthcare Professionals, 2004, ISBN 91-7373-971-5.

No 882 Robert Eklund: Disfluency in Swedish humanhuman and human-machine travel booking dialogues, 2004, ISBN 91-7373-966-9.

No 887 Anders Lindström: English and other Foreign Linguistic Elements in Spoken Swedish. Studies of Productive Processes and their Modelling using Finite-State Tools, 2004, ISBN 91-7373-981-2.

No 889 Zhiping Wang: Capacity-Constrained Production-inventory systems - Modelling and Analysis in both a traditional and an e-business context, 2004, ISBN 9185295-08-6.

No 893 Pernilla Qvarfordt: Eyes on Multimodal Interaction, 2004, ISBN 91-85295-30-2.

No 910 Magnus Kald: In the Borderland between Strategy and Management Control - Theoretical Framework and Empirical Evidence, 2004, ISBN 91-85295-82-5. 
No 918 Jonas Lundberg: Shaping Electronic News: Genre Perspectives on Interaction Design, 2004, ISBN 9185297-14-3.

No 900 Mattias Arvola: Shades of use: The dynamics of interaction design for sociable use, 2004, ISBN 9185295-42-6.

No 920 Luis Alejandro Cortés: Verification and Scheduling Techniques for Real-Time Embedded Systems, 2004, ISBN 91-85297-21-6.

No 929 Diana Szentivanyi: Performance Studies of FaultTolerant Middleware, 2005, ISBN 91-85297-58-5.

No 933 Mikael Cäker: Management Accounting as Constructing and Opposing Customer Focus: Three Case Studies on Management Accounting and Customer Relations, 2005, ISBN 91-85297-64-X.

No 937 Jonas Kvarnström: TALplanner and Other Extensions to Temporal Action Logic, 2005, ISBN 9185297-75-5.

No 938 Bourhane Kadmiry: Fuzzy Gain-Scheduled Visual Servoing for Unmanned Helicopter, 2005, ISBN 9185297-76-3.

No 945 Gert Jervan: Hybrid Built-In Self-Test and Test Generation Techniques for Digital Systems, 2005, ISBN 91-85297-97-6.

No 946 Anders Arpteg: Intelligent Semi-Structured Information Extraction, 2005, ISBN 91-85297-98-4.

No 947 Ola Angelsmark: Constructing Algorithms for Constraint Satisfaction and Related Problems - Methods and Applications, 2005, ISBN 91-85297-99-2.

No 963 Calin Curescu: Utility-based Optimisation of Resource Allocation for Wireless Networks, 2005, ISBN 91-85457-07-8

No 972 Björn Johansson: Joint Control in Dynamic Situations, 2005, ISBN 91-85457-31-0.

No 974 Dan Lawesson: An Approach to Diagnosability Analysis for Interacting Finite State Systems, 2005, ISBN 91-85457-39-6.

No 979 Claudiu Duma: Security and Trust Mechanisms for Groups in Distributed Services, 2005, ISBN 91-85457$54-X$.

No 983 Sorin Manolache: Analysis and Optimisation of Real-Time Systems with Stochastic Behaviour, 2005, ISBN 91-85457-60-4.

No 986 Yuxiao Zhao: Standards-Based Application Integration for Business-to-Business Communications, 2005, ISBN 91-85457-66-3.

No 1004 Patrik Haslum: Admissible Heuristics for Automated Planning, 2006, ISBN 91-85497-28-2.

No 1005 Aleksandra Tešanovic: Developing Reusable and Reconfigurable Real-Time Software using Aspects and Components, 2006, ISBN 91-85497-29-0.

No 1008 David Dinka: Role, Identity and Work: Extending the design and development agenda, 2006, ISBN 9185497-42-8.

No 1009 Iakov Nakhimovski: Contributions to the Modeling and Simulation of Mechanical Systems with Detailed Contact Analysis, 2006, ISBN 91-85497-43-X

No 1013 Wilhelm Dahllöf: Exact Algorithms for Exact Satisfiability Problems, 2006, ISBN 91-85523-97-6.

No 1016 Levon Saldamli: PDEModelica - A High-Level Language for Modeling with Partial Differential Equations, 2006, ISBN 91-85523-84-4.

No 1017 Daniel Karlsson: Verification of Component-based Embedded System Designs, 2006, ISBN 91-85523-79-8
No 1018 Ioan Chisalita: Communication and Networking Techniques for Traffic Safety Systems, 2006, ISBN 9185523-77-1.

No 1019 Tarja Susi: The Puzzle of Social Activity - The Significance of Tools in Cognition and Cooperation, 2006, ISBN 91-85523-71-2

No 1021 Andrzej Bednarski: Integrated Optimal Code Generation for Digital Signal Processors, 2006, ISBN 9185523-69-0.

No 1022 Peter Aronsson: Automatic Parallelization of Equation-Based Simulation Programs, 2006, ISBN 9185523-68-2.

No 1030 Robert Nilsson: A Mutation-based Framework for Automated Testing of Timeliness, 2006, ISBN 9185523-35-6.

No 1034 Jon Edvardsson: Techniques for Automatic Generation of Tests from Programs and Specifications, 2006, ISBN 91-85523-31-3.

No 1035 Vaida Jakoniene: Integration of Biological Data, 2006, ISBN 91-85523-28-3.

No 1045 Genevieve Gorrell: Generalized Hebbian Algorithms for Dimensionality Reduction in Natural Language Processing, 2006, ISBN 91-85643-88-2.

No 1051 Yu-Hsing Huang: Having a New Pair of Glasses Applying Systemic Accident Models on Road Safety, 2006, ISBN 91-85643-64-5.

No 1054 Åsa Hedenskog: Perceive those things which cannot be seen - A Cognitive Systems Engineering perspective on requirements management, 2006, ISBN 91-85643-57-2

No 1061 Cécile Åberg: An Evaluation Platform for Semantic Web Technology, 2007, ISBN 91-85643-31-9.

No 1073 Mats Grindal: Handling Combinatorial Explosion in Software Testing, 2007, ISBN 978-91-85715-74-9.

No 1075 Almut Herzog: Usable Security Policies for Runtime Environments, 2007, ISBN 978-91-85715-65-7.

No 1079 Magnus Wahlström: Algorithms, measures, and upper bounds for Satisfiability and related problems, 2007, ISBN 978-91-85715-55-8

No 1083 Jesper Andersson: Dynamic Software Architectures, 2007, ISBN 978-91-85715-46-6.

No 1086 Ulf Johansson: Obtaining Accurate and Comprehensible Data Mining Models - An Evolutionary Approach, 2007, ISBN 978-91-85715-34-3.

No 1089 Traian Pop: Analysis and Optimisation of Distributed Embedded Systems with Heterogeneous Scheduling Policies, 2007, ISBN 978-91-85715-27-5.

No 1091 Gustav Nordh: Complexity Dichotomies for CSPrelated Problems, 2007, ISBN 978-91-85715-20-6.

No 1106 Per Ola Kristensson: Discrete and Continuous Shape Writing for Text Entry and Control, 2007, ISBN 97891-85831-77-7

No 1110 He Tan: Aligning Biomedical Ontologies, 2007, ISBN 978-91-85831-56-2.

No 1112 Jessica Lindblom: Minding the body - Interacting socially through embodied action, 2007, ISBN 978-9185831-48-7.

No 1113 Pontus Wärnestål: Dialogue Behavior Management in Conversational Recommender Systems, 2007, ISBN 978-91-85831-47-0.

No 1120 Thomas Gustafsson: Management of Real-Time Data Consistency and Transient Overloads in Embedded Systems, 2007, ISBN 978-91-85831-33-3. 
No 1127 Alexandru Andrei: Energy Efficient and Predictable Design of Real-time Embedded Systems, 2007, ISBN 978-91-85831-06-7.

No 1139 Per Wikberg: Eliciting Knowledge from Experts in Modeling of Complex Systems: Managing Variation and Interactions, 2007, ISBN 978-91-85895-66-3.

No 1143 Mehdi Amirijoo: QoS Control of Real-Time Data Services under Uncertain Workload, 2007, ISBN 978 91-85895-49-6.

No 1150 Sanny Syberfeldt: Optimistic Replication with Forward Conflict Resolution in Distributed Real-Time Databases, 2007, ISBN 978-91-85895-27-4.

No 1155 Beatrice Alenljung: Envisioning a Future Decision Support System for Requirements Engineering - A Holistic and Human-centred Perspective, 2008, ISBN 978-91-85895-11-3.

No 1156 Artur Wilk: Types for XML with Application to Xcerpt, 2008, ISBN 978-91-85895-08-3.

No 1183 Adrian Pop: Integrated Model-Driven Development Environments for Equation-Based Object-Oriented Languages, 2008, ISBN 978-91-7393-895-2.

No 1185 Jörgen Skågeby: Gifting Technologies Ethnographic Studies of End-users and Social Media Sharing, 2008, ISBN 978-91-7393-892-1.

No 1187 Imad-Eldin Ali Abugessaisa: Analytical tools and information-sharing methods supporting road safety organizations, 2008, ISBN 978-91-7393-887-7.

No 1204 H. Joe Steinhauer: A Representation Scheme for Description and Reconstruction of Object Configurations Based on Qualitative Relations, 2008, ISBN 978-91-7393-823-5.

No 1222 Anders Larsson: Test Optimization for Core-based System-on-Chip, 2008, ISBN 978-91-7393-768-9.

No 1238 Andreas Borg: Processes and Models for Capacity Requirements in Telecommunication Systems, 2009, ISBN 978-91-7393-700-9.

No 1240 Fredrik Heintz: DyKnow: A Stream-Based Knowledge Processing Middleware Framework, 2009, ISBN 978-91-7393-696-5.

No 1241 Birgitta Lindström: Testability of Dynamic RealTime Systems, 2009, ISBN 978-91-7393-695-8.

No 1244 Eva Blomqvist: Semi-automatic Ontology Construction based on Patterns, 2009, ISBN 978-91-7393-683-5.

No 1249 Rogier Woltjer: Functional Modeling of Constraint Management in Aviation Safety and Command and Control, 2009, ISBN 978-91-7393-659-0.

No 1260 Gianpaolo Conte: Vision-Based Localization and Guidance for Unmanned Aerial Vehicles, 2009, ISBN 978-91-7393-603-3.

No 1262 AnnMarie Ericsson: Enabling Tool Support for Formal Analysis of ECA Rules, 2009, ISBN 978-91-7393598-2.

No 1266 Jiri Trnka: Exploring Tactical Command and Control: A Role-Playing Simulation Approach, 2009, ISBN 978-91-7393-571-5.

No 1268 Bahlol Rahimi: Supporting Collaborative Work through ICT - How End-users Think of and Adopt Integrated Health Information Systems, 2009, ISBN 978-91-7393-550-0.

No 1274 Fredrik Kuivinen: Algorithms and Hardness Results for Some Valued CSPs, 2009, ISBN 978-91-7393-525-8.

No 1281 Gunnar Mathiason: Virtual Full Replication for Scalable Distributed Real-Time Databases, 2009, ISBN 978-91-7393-503-6.
No 1290 Viacheslav Izosimov: Scheduling and Optimization of Fault-Tolerant Distributed Embedded Systems, 2009, ISBN 978-91-7393-482-4.

No1294 Johan Thapper: Aspects of a Constraint Optimisation Problem, 2010, ISBN 978-91-7393-464-0.

No 1306 Susanna Nilsson: Augmentation in the Wild: User Centered Development and Evaluation of Augmented Reality Applications, 2010, ISBN 978-917393-416-9.

No 1313 Christer Thörn: On the Quality of Feature Models, 2010, ISBN 978-91-7393-394-0.

No 1321 Zhiyuan He: Temperature Aware and DefectProbability Driven Test Scheduling for System-onChip, 2010, ISBN 978-91-7393-378-0.

No 1333 David Broman: Meta-Languages and Semantics for Equation-Based Modeling and Simulation, 2010, ISBN 978-91-7393-335-3.

No 1337 Alexander Siemers: Contributions to Modelling and Visualisation of Multibody Systems Simulations with Detailed Contact Analysis, 2010, ISBN 978-91-7393317-9.

No 1354 Mikael Asplund: Disconnected Discoveries: Availability Studies in Partitioned Networks, 2010, ISBN 978-91-7393-278-3.

No 1359 Jana Rambusch: Mind Games Extended: Understanding Gameplay as Situated Activity, 2010, ISBN 978-91-7393-252-3.

No 1373 Sonia Sangari: Head Movement Correlates to Focus Assignment in Swedish, 2011, ISBN 978-91-7393-1540 .

No 1374 Jan-Erik Källhammer: Using False Alarms when Developing Automotive Active Safety Systems, 2011, ISBN 978-91-7393-153-3.

No 1375 Mattias Eriksson: Integrated Code Generation, 2011, ISBN 978-91-7393-147-2

No 1381 Ola Leifler: Affordances and Constraints of Intelligent Decision Support for Military Command and Control - Three Case Studies of Support Systems, 2011, ISBN 978-91-7393-133-5

No 1386 Soheil Samii: Quality-Driven Synthesis and Optimization of Embedded Control Systems, 2011, ISBN 978-91-7393-102-1.

No 1419 Erik Kuiper: Geographic Routing in Intermittentlyconnected Mobile Ad Hoc Networks: Algorithms and Performance Models, 2012, ISBN 978-91-7519981-8.

No 1451 Sara Stymne: Text Harmonization Strategies for Phrase-Based Statistical Machine Translation, 2012, ISBN 978-91-7519-887-3.

No 1455 Alberto Montebelli: Modeling the Role of Energy Management in Embodied Cognition, 2012, ISBN 978-91-7519-882-8.

No 1465 Mohammad Saifullah: Biologically-Based Interactive Neural Network Models for Visual Attention and Object Recognition, 2012, ISBN 978-91-7519-838-5.

No 1490 Tomas Bengtsson: Testing and Logic Optimization Techniques for Systems on Chip, 2012, ISBN 978-917519-742-5.

No1481 David Byers: Improving Software Security by Preventing Known Vulnerabilities, 2012, ISBN 97891-7519-784-5.

No 1496 Tommy Färnqvist: Exploiting Structure in CSPrelated Problems, 2013, ISBN 978-91-7519-711-1. 
No 1503 John Wilander: Contributions to Specification, Implementation, and Execution of Secure Software, 2013, ISBN 978-91-7519-681-7.

No 1506 Magnus Ingmarsson: Creating and Enabling the Useful Service Discovery Experience, 2013, ISBN 978 91-7519-662-6.

No 1547 Wladimir Schamai: Model-Based Verification of Dynamic System Behavior against Requirements: Method, Language, and Tool, 2013, ISBN 978-917519-505-6.

No 1551 Henrik Svensson: Simulations, 2013, ISBN 978-917519-491-2.

No 1559 Sergiu Rafiliu: Stability of Adaptive Distributed Real-Time Systems with Dynamic Resource Management, 2013, ISBN 978-91-7519-471-4.

No 1581 Usman Dastgeer: Performance-aware Component Composition for GPU-based Systems, 2014, ISBN 978-91-7519-383-0.

No 1602 Cai Li: Reinforcement Learning of Locomotion based on Central Pattern Generators, 2014, ISBN 978-917519-313-7.

No 1652 Roland Samlaus: An Integrated Development Environment with Enhanced Domain-Specific Interactive Model Validation, 2015, ISBN 978-917519-090-7.

No 1663 Hannes Uppman: On Some Combinatorial Optimization Problems: Algorithms and Complexity, 2015, ISBN 978-91-7519-072-3.

No 1664 Martin Sjölund: Tools and Methods for Analysis, Debugging, and Performance Improvement of Equation-Based Models, 2015, ISBN 978-91-7519-071-6.

No 1666 Kristian Stavåker: Contributions to Simulation of Modelica Models on Data-Parallel Multi-Core Architectures, 2015, ISBN 978-91-7519-068-6.

No 1680 Adrian Lifa: Hardware/Software Codesign of Embedded Systems with Reconfigurable and Heterogeneous Platforms, 2015, ISBN 978-91-7519-0402.

No 1685 Bogdan Tanasa: Timing Analysis of Distributed Embedded Systems with Stochastic Workload and Reliability Constraints, 2015, ISBN 978-91-7519-022-8.

No 1691 Håkan Warnquist: Troubleshooting Trucks Automated Planning and Diagnosis, 2015, ISBN 97891-7685-993-3.

No 1702 Nima Aghaee: Thermal Issues in Testing of Advanced Systems on Chip, 2015, ISBN 978-91-7685949-0.

No 1715 Maria Vasilevskaya: Security in Embedded Systems: A Model-Based Approach with Risk Metrics, 2015, ISBN 978-91-7685-917-9.

No 1729 Ke Jiang: Security-Driven Design of Real-Time Embedded System, 2016, ISBN 978-91-7685-884-4.

No 1733 Victor Lagerkvist: Strong Partial Clones and the Complexity of Constraint Satisfaction Problems: Limitations and Applications, 2016, ISBN 978-91-7685856-1.

No 1734 Chandan Roy: An Informed System Development Approach to Tropical Cyclone Track and Intensity Forecasting, 2016, ISBN 978-91-7685-854-7.

No 1746 Amir Aminifar: Analysis, Design, and Optimization of Embedded Control Systems, 2016, ISBN 978-917685-826-4.

No 1747 Ekhiotz Vergara: Energy Modelling and Fairness for Efficient Mobile Communication, 2016, ISBN 978-917685-822-6.
No 1748 Dag Sonntag: Chain Graphs - Interpretations, Expressiveness and Learning Algorithms, 2016, ISBN 978-91-7685-818-9.

No 1768 Anna Vapen: Web Authentication using ThirdParties in Untrusted Environments, 2016, ISBN 97891-7685-753-3.

No 1778 Magnus Jandinger: On a Need to Know Basis: A Conceptual and Methodological Framework for Modelling and Analysis of Information Demand in an Enterprise Context, 2016, ISBN 978-91-7685-713-7.

No 1798 Rahul Hiran: Collaborative Network Security: Targeting Wide-area Routing and Edge-network Attacks, 2016, ISBN 978-91-7685-662-8.

No 1813 Nicolas Melot: Algorithms and Framework for Energy Efficient Parallel Stream Computing on Many-Core Architectures, 2016, ISBN 978-91-7685623-9.

No 1823 Amy Rankin: Making Sense of Adaptations: Resilience in High-Risk Work, 2017, ISBN 978-917685-596-6.

No 1831 Lisa Malmberg: Building Design Capability in the Public Sector: Expanding the Horizons of Development, 2017, ISBN 978-91-7685-585-0.

No 1851 Marcus Bendtsen: Gated Bayesian Networks, 2017, ISBN 978-91-7685-525-6.

No 1852 Zlatan Dragisic: Completion of Ontologies and Ontology Networks, 2017, ISBN 978-91-7685-522-5.

No 1854 Meysam Aghighi: Computational Complexity of some Optimization Problems in Planning, 2017, ISBN 978-91-7685-519-5.

No 1863 Simon Ståhlberg: Methods for Detecting Unsolvable Planning Instances using Variable Projection, 2017, ISBN 978-91-7685-498-3.

No 1879 Karl Hammar: Content Ontology Design Patterns: Qualities, Methods, and Tools, 2017, ISBN 978-917685-454-9.

No 1887 Ivan Ukhov: System-Level Analysis and Design under Uncertainty, 2017, ISBN 978-91-7685-426-6.

No 1891 Valentina Ivanova: Fostering User Involvement in Ontology Alignment and Alignment Evaluation, 2017, ISBN 978-91-7685-403-7.

No 1902 Vengatanathan Krishnamoorthi: Efficient HTTPbased Adaptive Streaming of Linear and Interactive Videos, 2018, ISBN 978-91-7685-371-9.

No 1903 Lu Li: Programming Abstractions and Optimization Techniques for GPU-based Heterogeneous Systems, 2018, ISBN 978-91-7685-370-2.

No1913 Jonas Rybing: Studying Simulations with Distributed Cognition, 2018, ISBN 978-91-7685-348-1.

No 1936 Leif Jonsson: Machine Learning-Based Bug Handling in Large-Scale Software Development, 2018, ISBN 978-91-7685-306-1.

No 1964 Arian Maghazeh: System-Level Design of GPUBased Embedded Systems, 2018, ISBN 978-91-7685175-3.

No 1967 Mahder Gebremedhin: Automatic and Explicit Parallelization Approaches for Equation Based Mathematical Modeling and Simulation, 2019, ISBN 978-91-7685-163-0.

No 1984 Anders Andersson: Distributed Moving Base Driving Simulators - Technology, Performance, and Requirements, 2019, ISBN 978-91-7685-090-9.

No 1993 Ulf Kargén: Scalable Dynamic Analysis of Binary Code, 2019, ISBN 978-91-7685-049-7. 
No 2001 Tim Overkamp: How Service Ideas Are Implemented: Ways of Framing and Addressing Service Transformation, 2019, ISBN 978-91-7685-025-1.

No 2006 Daniel de Leng: Robust Stream Reasoning Under Uncertainty, 2019, ISBN 978-91-7685-013-8.

No 2048 Biman Roy: Applications of Partial Polymorphisms in (Fine-Grained) Complexity of Constraint Satisfaction Problems, 2020, ISBN 978-91-7929-898-2.

No 2051 Olov Andersson: Learning to Make Safe Real-Time Decisions Under Uncertainty for Autonomous Robots, 2020, ISBN 978-91-7929-889-0.

No 2065 Vanessa Rodrigues: Designing for Resilience: Navigating Change in Service Systems, 2020, ISBN 978-91-7929-867-8.

No 2082 Robin Kurtz: Contributions to Semantic Dependency Parsing: Search, Learning, and Application, 2020, ISBN 978-91-7929-822-7.

No 2108 Shanai Ardi: Vulnerability and Risk Analysis Methods and Application in Large Scale Development of Secure Systems, 2021, ISBN 978-917929-744-2.

No 2125 Zeinab Ganjei: Parameterized Verification of Synchronized Concurrent Programs, 2021, ISBN 97891-7929-697-1.

\section{Linköping Studies in Arts and Sciences}

No 504 Ing-Marie Jonsson: Social and Emotional Characteristics of Speech-based In-Vehicle Information Systems: Impact on Attitude and Driving Behaviour, 2009, ISBN 978-91-7393-478-7.

No 586 Fabian Segelström: Stakeholder Engagement for Service Design: How service designers identify and communicate insights, 2013, ISBN 978-91-7519-554-4.

No 618 Johan Blomkvist: Representing Future Situations of Service: Prototyping in Service Design, 2014, ISBN 978-91-7519-343-4.

No 620 Marcus Mast: Human-Robot Interaction for SemiAutonomous Assistive Robots, 2014, ISBN 978-917519-319-9.

No 677 Peter Berggren: Assessing Shared Strategic Understanding, 2016, ISBN 978-91-7685-786-1.

No 695 Mattias Forsblad: Distributed cognition in home environments: The prospective memory and cognitive practices of older adults, 2016, ISBN 97891-7685-686-4.

No 787 Sara Nygårdhs: Adaptive behaviour in traffic: An individual road user perspective, 2020, ISBN 978-917929-857-9.

No 811 Sam Thellman: Social Robots as Intentional Agents, 2021, ISBN 978-91-7929-008-5.

\section{Linköping Studies in Statistics}

No 9 Davood Shahsavani: Computer Experiments Designed to Explore and Approximate Complex Deterministic Models, 2008, ISBN 978-91-7393-976-8.

No 10 Karl Wahlin: Roadmap for Trend Detection and Assessment of Data Quality, 2008, ISBN 978-91-7393792-4.

No 11 Oleg Sysoev: Monotonic regression for large multivariate datasets, 2010, ISBN 978-91-7393-412-1.

No 13 Agné Burauskaite-Harju: Characterizing Temporal Change and Inter-Site Correlations in Daily and Subdaily Precipitation Extremes, 2011, ISBN 978-91-7393110-6.
No 14 Måns Magnusson: Scalable and Efficient Probabilistic Topic Model Inference for Textual Data, 2018, ISBN 978-91-7685-288-0.

No 15 Per Sidén: Scalable Bayesian spatial analysis with Gaussian Markov random fields, 2020, 978-91-7929818-0.

\section{Linköping Studies in Information Science}

No 1 Karin Axelsson: Metodisk systemstrukturering- att skapa samstämmighet mellan informationssystemarkitektur och verksamhet, 1998. ISBN 9172-19-296-8.

No 2 Stefan Cronholm: Metodverktyg och användbarhet en studie av datorstödd metodbaserad systemutveckling, 1998, ISBN 9172-19-299-2.

No 3 Anders Avdic: Användare och utvecklare - om anveckling med kalkylprogram, 1999. ISBN 91-7219606-8.

No 4 Owen Eriksson: Kommunikationskvalitet hos informationssystem och affärsprocesser, 2000, ISBN 917219-811-7.

No 5 Mikael Lind: Från system till process - kriterier för processbestämning vid verksamhetsanalys, 2001, ISBN 91-7373-067-X

No 6 Ulf Melin: Koordination och informationssystem i företag och nätverk, 2002, ISBN 91-7373-278-8.

No 7 Pär J. Ågerfalk: Information Systems Actability - Understanding Information Technology as a Tool for Business Action and Communication, 2003, ISBN 917373-628-7.

No 8 Ulf Seigerroth: Att förstå och förändra systemutvecklingsverksamheter - en taxonomi för metautveckling, 2003, ISBN 91-7373-736-4

No 9 Karin Hedström: Spår av datoriseringens värden Effekter av IT i äldreomsorg, 2004, ISBN 91-7373-9634.

No 10 Ewa Braf: Knowledge Demanded for Action Studies on Knowledge Mediation in Organisations, 2004, ISBN 91-85295-47-7.

No 11 Fredrik Karlsson: Method Configuration method and computerized tool support, 2005, ISBN 91-8529748-8.

No 12 Malin Nordström: Styrbar systemförvaltning - Att organisera systemförvaltningsverksamhet med hjälp av effektiva förvaltningsobjekt, 2005, ISBN 91-8529760-7.

No 13 Stefan Holgersson: Yrke: POLIS - Yrkeskunskap, motivation, IT-system och andra förutsättningar för polisarbete, 2005, ISBN 91-85299-43-X.

No 14 Benneth Christiansson, Marie-Therese Christiansson: Mötet mellan process och komponent - mot ett ramverk för en verksamhetsnära kravspecifikation vid anskaffning av komponentbaserade informationssystem, 2006, ISBN 91-85643$22-X$ 


\section{FACULTY OF ARTS AND SCIENCES}

Linköping Studies in Arts and Sciences No. 811, 2021

Department of Computer and Information Science

Linköping University

SE-581 83 Linköping, Sweden

www.liu.se 